\title{
SHORT-SELLERS AND ANALYSTS AS PROVIDERS OF COMPLEMENTARY INFORMATION ABOUT FUTURE FIRM PERFORMANCE
}

\author{
A Dissertation \\ by \\ MICHAEL STEPHEN DRAKE \\ Submitted to the Office of Graduate Studies of \\ Texas A\&M University \\ in partial fulfillment of the requirements for the degree of \\ DOCTOR OF PHILOSOPHY
}

May 2009

Major Subject: Accounting 


\title{
SHORT-SELLERS AND ANALYSTS AS PROVIDERS OF COMPLEMENTARY INFORMATION ABOUT FUTURE FIRM PERFORMANCE
}

\author{
A Dissertation \\ by \\ MICHAEL STEPHEN DRAKE \\ Submitted to the Office of Graduate Studies of \\ Texas A\&M University \\ in partial fulfillment of the requirements for the degree of \\ DOCTOR OF PHILOSOPHY
}

\begin{abstract}
Approved by:
Chair of Committee, Senyo Tse

Committee Members, Ekkehart Boehmer

James N. Myers III

Lynn L. Rees

Head of Department, James J. Benjamin
\end{abstract}

May 2009

Major Subject: Accounting 


\begin{abstract}
Short-sellers and Analysts as Providers of Complementary Information about Future

Firm Performance. (May 2009)

Michael Stephen Drake, B.S., Brigham Young University;

M.Acc., Brigham Young University

Chair of Advisory Committee: Dr. Senyo Tse
\end{abstract}

This study examines whether short-sellers and financial analysts develop complementary information about future earnings and returns and assesses whether investors can improve predictions made by each of these intermediaries using information provided by the other. The first main result is that the relative short interest ratio (shares sold short divided by total shares outstanding) contains information that is useful for predicting future earnings, beyond (i.e., incremental to) the information in analyst forecasts. I also find that analysts do not fully incorporate short interest information into their forecasts and demonstrate that analyst forecasts can be improved (i.e., can be made to be less biased and more accurate) by adjusting for short interest information. The second main result is that analyst forecast revisions contain information that is useful for predicting future abnormal returns, beyond the information in the relative short interest ratio. I demonstrate that portfolios of stocks formed based on consistent signals from short-sellers and analysts produce abnormal return spreads that are significantly larger than spreads produced by portfolios formed using signals 
from short-sellers alone. Collectively, the evidence suggests that short-sellers and analyst provide complementary information about future firm performance that is useful to investors. 


\section{DEDICATION}

To my father, Terrance Stephen Drake, the "real" doctor in the family. 


\section{ACKNOWLEDGEMENTS}

I thank my committee chair, Senyo Tse, and my committee members, Ekkehart Boehmer, Lynn Rees, and James Myers for their guidance and support throughout the course of this research. I also thank Ed Swanson for sharing his short interest data and Anwer Ahmed, Kris Allee, Cory Cassell, Linda Myers, Stephanie Rasmussen, Jaime Schmidt, Nate Sharp, Anne Thompson, Jake Thornock, Chris Williams, Rebecca Wynalda for helpful comments. I also want to extend my gratitude to the Mays Business School and the Deloitte \& Touche Foundation for generous financial support. Finally, thanks to my wife, McKenzie, and my children, Gavin and Abbie for their love, patience, prayers, and humor. 


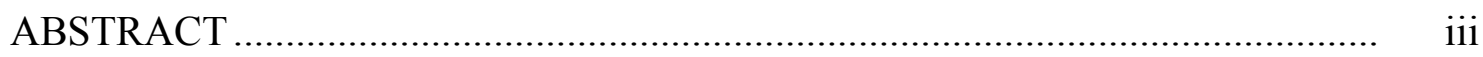

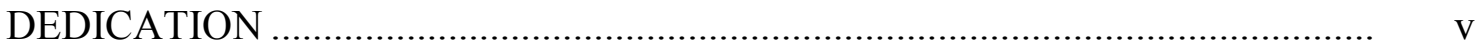

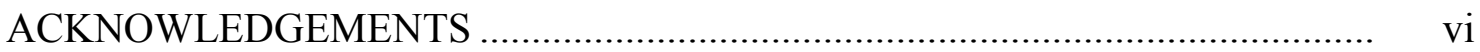

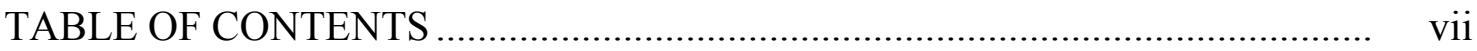

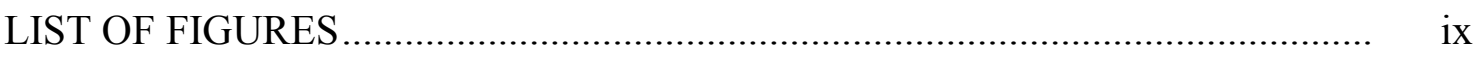



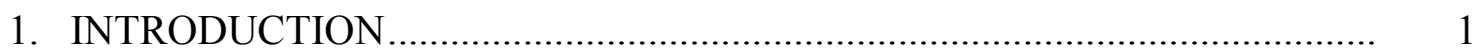

2. LITERATURE REVIEW AND EMPIRICAL PREDICTIONS ........................ 8

2.1. Background on Short-Selling ............................................................ 8

2.2. Relevant Literature on Short-Selling................................................ 10

2.3. Relevant Literature on Financial Analysts ......................................... 16

2.4. Motivation ................................................................................. 19

2.5. Empirical Predictions ..................................................................... 20

3. SAMPLE SELECTION, VARIABLE MEASUREMENT, AND DESCRIPTIVE STATISTICS ................................................................ 24

3.1. Sample Selection and Variable Measurement...................................... 24

3.2. Descriptive Statistics .......................................................................... 26

4. EMPIRICAL MODELS AND RESULTS ………........................................... 34

4.1. The Incremental Information Content of Short Interest for Future Earnings beyond Analyst Forecasts .................................... 34

4.2. Assessing Analyst Efficiency with Respect to Short Interest .............. 47

4.3. Adjusting Analyst Forecasts for Short Interest ................................... 54

4.4. The Incremental Information Content of Analyst Forecast Revisions for Future Returns beyond Short Interest ........................... $\quad 57$ 




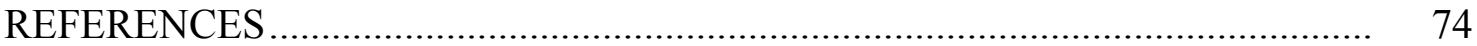

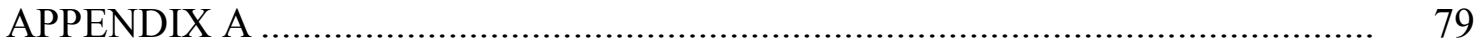

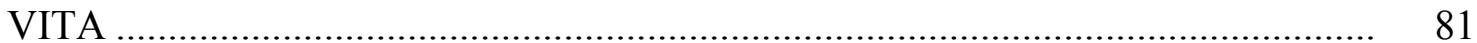




\section{LIST OF FIGURES}

FIGURE Page

$1 \quad$ Mean and Median Relative Short Interest Ratios over Time ................... 10

2 Timing of Variable Measurement .................................................... 27

3 Mean and Median Future Accounting Profitability across

Relative Short Interest Ratio Portfolios ............................................... 35

4 Six-Month Abnormal Returns to Portfolios Formed Using Short

Interest or Short Interest and Analyst Forecast Revisions .................... 62 


\section{LIST OF TABLES}

TABLE Page

$1 \quad$ Descriptive Statistics ...................................................................... 28

2 Transition Matrix for Changes in Short Interest Portfolio Membership over the Next Two Quarters .................................................. $\quad 32$

3 The Association between Short Interest and Quarter-One Earnings with and without Controlling for Analyst Forecasts ................................ 40

4 The Association between Short Interest and Quarter-Two Earnings with and without Controlling for Analyst Forecasts

5 The Association between Short Interest and Quarter-One and Quarter-Two Forecast Errors

6 Comparisons of Error and Squared-Error of Unadjusted Analyst Forecasts to Forecasts Adjusted with Short Interest Information

7 The Association between Analyst Forecast Revisions and Subsequent Abnormal Returns with and without Controlling for Short Interest

8 Abnormal Returns to Portfolios Formed Using Short Interest or Short Interest and Analyst Forecast Revisions

9 Four-Factor Regression Results for Portfolios Formed Using Short Interest

10 Four-Factor Regression Results for Portfolios Formed Using Short Interest and Analyst Forecast Revisions..... 


\section{INTRODUCTION}

Short-sellers are informed investors who take positions in firms whose stock price they expect to underperform in the future. Since short-sellers profit by anticipating stock price declines, they are broadly labeled by the financial press as "bears" or pessimistic investors. In contrast, financial analysts are generally characterized as being overly optimistic about future stock and earnings performance. ${ }^{1}$ While extensive research investigates financial analysts role as information intermediaries, recent research takes initial steps at examining the potential role of short-sellers as information intermediaries in the capital markets (Pownall and Simko 2005; Akbas et al 2008). The objective of this study is to investigate whether short-sellers and analysts develop complementary information about future firm performance and to assess whether investors can improve predictions made by one intermediary by using information provided by the other.

I investigate short-sellers and analysts because they both predict future firm performance and because their incentives make it likely that they develop different types of value-relevant information. Short-sellers seek to profit from their predictions of stock price declines. Analysts predict earnings and must balance incentives to make accurate predictions with incentives to maintain relationships with management (Francis and

This dissertation follows the style of The Accounting Review.

${ }^{1}$ This characterization is based on the distributions of stock recommendations, which prior research finds to be heavily skewed towards "buy" and of analyst forecast errors, which prior research finds to be negative on average. See, for example, Abarbanell (1991), Ali et al. (1992), McNichols and O'Brien (1997), Easterwood and Nutt (1999), and Bradshaw et al. (2001). 
Philbrick 1993; Lim 2001). ${ }^{2}$ These differences suggest that short sellers and analysts uncover unique information and that investors may be able to infer incremental information about future performance from each intermediary. The similarities and differences between short-sellers and analysts motivate my two research questions.

My first research question is whether short interest positions contain information that is useful for predicting future earnings, beyond the information available from analyst earnings forecasts. Extant research suggests that short-sellers are informed about future stock price movements (Diamond and Verrecchia 1987; Asquith and Meulbroek 1996; Dechow et al. 2001; Desai et al. 2002; Asquith et al. 2005; Boehmer et al. 2008). The information used by short-sellers to predict returns is also likely to predict earnings because short-sellers may discover information related to future earnings news that other market participants do not have or short-sellers may uncover price-relevant information on events that will be reflected in current or future earnings (Collins et al. 1987; Warfield and Wild 1992). ${ }^{3}$ However, analyst forecasts may not fully reflect information from short-sellers. Analysts may be reluctant to damage relationships with management by updating their forecasts with pessimistic information (Francis and Philbrick 1993; Lim 2001), and they may under-react to the information because they view short interest as an unreliable signal about future earnings (Abarbanell 1991; Abarbanell and Bernard

\footnotetext{
${ }^{2}$ Issuing earnings forecast is just one of a group of services that sell-side analysts provide to their clients (e.g., they also issue stock recommendations, target prices, and growth forecasts). I focus solely on earnings forecasts because one of the objectives of my study is to investigate whether short-sellers and analysts develop complementary information about future earnings.

${ }^{3}$ For example, a short-seller might take a short position based on information about the future product recalls. Here, the negative stock price reaction at the time of the recall announcement will occur before the earnings effects of the recalls are recognized.
} 
1992). If the short interest information is not fully subsumed by analyst forecasts, then investors could improve the accuracy of those forecasts by incorporating short interest information.

My second research question is whether analyst earnings forecasts (i.e., forecast revisions) contain information that is useful for predicting future abnormal returns, beyond the information available in short interest. Short interest positions reflect shortsellers' predictions of future stock price performance. In contrast, analysts' earnings forecasts focus on reported earnings, and are not intended to predict returns. Nevertheless, prior studies find that analyst forecast revisions are positively associated with subsequent returns (Mendenhall 1991; Stickel 1991; Chan et al. 1996; Shane and Brous 2001; Barth and Hutton 2004), which suggests that analyst forecast revisions can be used to predict future returns. Thus, I also examine the extent to which forecast revisions contain information that is incrementally useful for predicting future returns by testing whether short interest fully subsumes the information in analyst forecast revisions. If the information in forecast revisions is not fully subsumed by short interest, then investors could improve their returns predictions using short interest by incorporating information provided by financial analysts.

I address my research questions using a large sample of monthly short interest data from 1988 to 2002 for firms listed on the New York Stock Exchange (NYSE), the American Stock Exchange (AMEX), and NASDAQ Stock Exchange. My short interest variable is the relative short interest (RSI) ratio, calculated as shares sold short divided by total shares outstanding. My analysis is based on two sets of empirical tests. 
The first set of tests investigates whether short interest positions contain information that is useful for predicting future earnings, beyond the information in analyst forecasts. I find that the RSI ratio is negatively associated with earnings levels and changes disclosed in the next two quarterly earnings announcements, which I label "quarter-one" and "quarter-two" respectively. ${ }^{4}$ These associations hold after controlling for the information in the consensus analyst forecast, prior period earnings, prior period returns, and various firm characteristics (e.g., size, book-to-market). I also find that the strength of the association between the RSI ratio and earnings levels and changes are statistically equivalent in quarter-one and quarter-two. This evidence is consistent with short-sellers' use of information that predicts earnings, and with that information not being fully embedded in the consensus earnings forecast.

I also find that the RSI ratio is negatively associated with analyst forecast errors (actual EPS minus forecast EPS) in quarter-one and in quarter-two. This result is robust to controls for variables that prior studies find to be significantly associated with forecasts errors and suggests that analyst forecasts do not fully reflect short interest information. Third, I demonstrate that consensus analyst forecasts can be improved by adjusting the forecasts for information in short interest about future earnings. Specifically, I adjust current-period analyst forecasts using the historical relationship between RSI ratios and analyst forecast errors. I find that adjusted consensus analyst

\footnotetext{
${ }^{4}$ I focus on the $t w o$ earnings announcements subsequent to the short interest measurement date because although examining the association between short interest and quarter-one earnings is the natural starting point, changes in prices generally lead changes in earnings (Collins et al. 1987; Warfield and Wild 1992). Thus, I also examine quarter-two earnings. This allows me to investigate whether any associations hold over a longer earnings horizon.
} 
forecasts are significantly less biased and more accurate than are the raw consensus analyst forecasts.

The second set of tests investigates whether analyst forecast revisions contain information that is useful for predicting future abnormal returns beyond the information in short interest. I find that analyst forecast revisions are positively associated with abnormal returns over the six months following the forecast revision date, after controlling for the information in the RSI ratio and for other common risk factors (i.e., size, book-to-market, momentum). ${ }^{5}$ This suggests that analyst forecast revisions contain information that is incrementally useful for predicting future returns, beyond the information in short interest.

Next, I demonstrate that portfolios of stocks formed based on information from both short-sellers and analysts produce larger spreads in future abnormal returns than do portfolios of stocks formed based on information from short-sellers alone. Specifically, I find a nearly monotonic negative relationship between portfolios of RSI ratios and future abnormal returns. The lowest portfolio of RSI ratios earns significant abnormal returns of $3.0 \%$ over the following 6 months, while the highest portfolio earns significant abnormal returns of $-3.7 \%$ over the same period, resulting in a return spread of $6.7 \%$. When I partition each short interest decile into three portfolios based on the sign of the consensus analyst revision (i.e., positive revision, no revision, or negative revision), I find that the return spread between portfolios formed based on consistent signals is larger than the return spread based on short interest alone. Specifically, the return spread

\footnotetext{
${ }^{5}$ All returns results are qualitatively similar using a 3-month horizon.
} 
between the portfolio with the lowest RSI ratios and positive consensus forecast revisions (so good news \& good news) the portfolio with the highest RSI ratios and negative consensus forecast revisions (so bad news \& bad news) is $12.2 \%$.

Finally, since the portfolio return analyses described above are based on stock returns adjusted for the market return only, I re-perform the portfolio analyses using alphas estimated from a four-factor regression model. This allows me to control for additional risk factors that are correlated with returns (i.e., market return, size, book-tomarket, and momentum). I find that the portfolio results are robust to these additional controls.

Taken together, the results from these empirical tests suggest that short-sellers and financial analysts develop complementary information about future earnings and returns. The results also demonstrate that predictions made by one intermediary can be improved upon by incorporating information provided by the other intermediary.

Broadly, these results contribute to the literature by illustrating the benefits of incorporating information from multiple intermediaries when predicting future firm performance. Specifically, the results imply that investors who use analyst forecasts to make investment decisions (e.g., in valuation models) can benefit from adjusting the analyst forecasts using short interest information. The results also imply that investors may benefit from taking long positions in stocks with low RSI ratios and positive consensus forecast revisions and that they should be particularly wary of holding long positions in stocks with high RSI ratios and negative consensus forecast revisions. 
In addition to its investment implications, this study contributes to several streams of literature. I contribute to the earnings prediction and short interest literatures by showing that short interest positions contain information that is useful for predicting earnings levels and changes disclosed in the next two earnings announcements. The results complement prior research by providing additional evidence that short-sellers possess value-relevant information. I contribute to the analyst forecast literature by documenting that analyst forecasts do not fully reflect short interest information. Finally, I show that the signal in high levels of short interest (e.g., bad news may be on the horizon) can be further refined by using analyst forecast revisions.

The remainder of this dissertation is organized as follows. In Section 2, I provide some background on short-selling, discuss the relevant literature, and develop my hypotheses. In Section 3, I discuss my sample selection criteria and variable measurements, and I provide descriptive statistics. Section 4 presents the empirical models and results. Section 5 concludes. 


\section{LITERATURE REVIEW AND EMPIRICAL PREDICTIONS}

In this section, I begin by providing some background on short-selling in the United States. I then review relevant studies that examine the activities of short-sellers and financial analysts in the capital markets. Finally, I motivate and present my empirical predictions.

\subsection{Background on Short-Selling}

A short sale is defined by the Securities and Exchange Commission (SEC) as "the sale of a security that the seller does not own or that the seller owns but does not deliver" (SEC 1999). In a typical short sale, the investor borrows shares from current stock owners for a fee and then sells the shares at the current stock price in the open market. ${ }^{6}$ At a future date, the investor closes the short position by buying back the shares in the open market, and then returning the shares to the lender. Thus, a short position is profitable when the stock price declines, and a short-seller's maximum theoretical profit is realized when the stock price falls to zero.

Investors take short positions in firms for a variety of reasons. For example, they may believe that the stock is over-valued based on publicly available information, or they may have private information about future bad news. Investors also take short positions as part of merger- or convertible-debt arbitrage strategies. In a mergerarbitrage strategy, investors take long positions in the target-firm and short positions in the acquiring-firm. Here, the investors assume that the target-firm is trading below its

\footnotetext{
${ }^{6}$ Brokerage houses typically have their own stock loan department from which investors can borrow stock.
} 
acquisition price per share. They believe that the target-firm's stock price will rise to reflect the acquisition price and that the acquiring-firm's stock price will fall to reflect the per-share cost of the acquisition. In a convertible debt-arbitrage strategy, investors buy the convertible debt of a firm and simultaneously take short positions in the stock of that firm. Here, the investors hedge their investment in the convertible debt, which they believe is undervalued, by selling the stock short. ${ }^{7}$

The nature of the short position carries additional risks and costs relative to taking the more traditional long position. The theoretical downside risk to a short position increases without limit as the stock price rises, which is in stark contrast to the limited liability of a long position. Short positions are also susceptible to recall risk and to short squeezes. Recall occurs when the lender recalls the loan of shares and the investor is required to cover the position prematurely. A short squeeze occurs when the stock price begins to rise and short-sellers are forced to close their positions by buying shares, which further increases the stock price and leads to further losses. Finally, there is a significant opportunity cost associated with short positions because the proceeds from the short-sale of a stock are not immediately available to the short-seller, but are held in an escrow account until the position is closed. This is costly to the short-seller because the proceeds cannot be invested elsewhere.

The magnitude of RSI ratios in the U.S. market has increased considerably over

\footnotetext{
${ }^{7}$ These arbitrage-motivated short positions generally exploit relative price movements of the two securities and do not reflect the investors' expectations about a given firm's future stock price declines and/or future earnings. As such they add noise to my empirical analyses, which biases against my finding results (Dechow et al. 2001).
} 
the past few decades. Figure 1 plots the mean and median RSI ratio over my sample period. Dechow et al. (2001) find similar increases in the RSI ratio using firms traded on the NYSE and AMEX stock exchanges from 1976 through 1993. The increase in RSI ratios over time is generally attributed to the emergence of hedge funds and to the deregulation of short-sale constraints (Dechow et al. 2001).

\section{FIGURE 1 \\ Mean and Median Relative Short Interest Ratios over Time}



Figure 1 reports the mean and median relative short interest ratio calculated by calendar year. The sample consists of 90,427 firm-quarter observations from the NYSE, AMEX, and NASDAQ stock exchanges for the 1988 to 2002 time-period.

\subsection{Relevant Literature on Short-Selling}

Diamond and Verrecchia (1987) suggest that only informed traders who have strong beliefs that a significant stock price decline will occur in the near-term will choose to sell stock short. This follows the idea that the high costs of short-selling are 
likely to drive out uninformed traders, so that prices reflect trades by more informed investors. Their theoretical model demonstrates that an unexpected increase in short interest predicts a price decline.

Subsequent to Diamond and Verrecchia (1987), several empirical studies tested the theoretical prediction that short interest predicts negative returns. Brent et al. (1990) use a small sample of approximately 200 stocks and find no evidence that short interest predicts returns in the month following an increase in short interest. However, they do find that high short interest is significantly associated with high betas and the presence of stock options and convertible securities, leading the authors to conclude that arbitrage and hedging strategies drive short interest changes. Senchack and Stark (1993) reexamine the relation between substantial increases in short interest and returns using a larger and more refined sample than that used by Brent et al. (1990). Specifically, they investigate 2,400 stocks with large percentage increases in short interest that meet three conditions: (i) the stock's short interest information is published in the Wall Street Journal, (ii) the stock has not been reported as being a target for arbitrage short-selling, and (iii) the reported change in short interest is greater than $100 \%$ over the prior month. These requirements are important because they likely purge the sample of noninformation based short-selling. The authors investigate 30 trading days of returns centered on the short interest publication date and, consistent with the prediction of Diamond and Verrecchia (1987), find small negative abnormal returns after the announcement in this short window. 
The empirical studies just mentioned investigate returns to changes in short interest positions over relatively short windows (e.g., one month or less). Asquith and Meulbroek (1996) is the first study to examine the long-run returns to portfolios of stocks with extremely high levels of short interest as measured by RSI ratios. Using stocks in the $95^{\text {th }}$ percentile of RSI ratios, they find average size-adjusted returns of $18 \%$ when the stock remains at this level of short interest. Over the two-year period subsequent to dropping out of the $95^{\text {th }}$ percentile, the average size-adjusted return is 23\%. Subsequent to Asquith and Meulbroek (1996), several empirical papers use a similar long-window approach and find that portfolios of stocks with high levels of short interest are associated with negative subsequent returns (see, e.g., Dechow et al. 2001; Desai et al. 2002; Asquith et al. 2005).

In recent years, daily and intraday short interest data has become available for academic research. These data provide a much richer set of information than the monthly short interest measure used in early research. Boehmer et al. (2008) investigate whether short-sellers are informed investors using daily NYSE order data. They find that on average short-sellers are "extremely well informed." They demonstrate that portfolios of heavily shorted stocks underperform portfolios of lightly shorted stocks by $1.16 \%$ over a period of 20 trading days (15.6\% annualized), after adjusting for risk. Overall, the results of the empirical studies which investigate the association between short interest and subsequent returns offer two broad conclusions relevant to this studyfirst, that short-sellers are informed about future returns and, second, that the ability of the RSI ratio to predict returns increases with the level of short interest. 
Another stream in the short-selling literature investigates short-sellers' trading strategies. In general, this literature seeks to better understand how short-sellers identify their targets. Dechow et al. (2001) find that short-selling is consistent with trading strategies based on fundamental analysis. Specifically, they find that short-sellers take positions in stocks with relatively low fundamental-to-price ratios. ${ }^{8}$ Cao et al. (2007) find that short-sellers exploit post-earnings-announcement drift and the accrual anomaly by taking short positions in firms that announce negative earnings surprises and/or that announce earnings with a high accrual component. Desai et al. (2007) find that shortsellers are more likely to target firms with large increases in sales, gross margin, and selling, general, and administrative expenses.

A third line of research investigates whether short-sellers appear to anticipate announcements of bad news. Using restatement announcements, Efendi et al. (2005) and Desai et al. (2006) find that short-sellers take positions in firms several months in advance of earnings restatement announcements, suggesting that short-sellers target firms with poor earnings quality. Griffin (2003) finds that short interest increases significantly in the months leading up to restatements made by firms that later face allegations of fraud in class action law-suits. Akbas et al. (2008) find that short interest levels are negatively associated with subsequent bad news announcements of various types. ${ }^{9}$

\footnotetext{
${ }^{8}$ Dechow et al. (2001) investigate four fundamental-to-price ratios: cash-flow-to-price; earnings-to-price; book-to-market; and value-to-market.

${ }^{9}$ Akbas et al. (2008) measure public news using the database of news headlines from Chan (2003). The database consists of news items from the Dow Jones Interactive Publications Library. In Chan (2003), a reading of each news headline was used to determine whether the news item revealed good, bad, or no news. See Table 3 of Chan (2003), for examples of each news classification.
} 
Extant research has also taken initial steps to address the question of whether short-sellers anticipate future earnings news. ${ }^{10}$ Christophe et al. (2004) investigate daily short interest over the five days preceding earnings announcements. They find that short-sellers significantly increase their positions before negative earnings surprises. What is unique about Christophe et al. (2004) is their use of a proprietary dataset of daily short interest. However, the use of this dataset constrains their sample to only 913 NASDAQ stocks from September 13 through December 12, 2000, which raises concerns about whether their sample is representative of firms listed on other exchanges and of short interest behavior in other time periods. Daske et al. (2005) re-examine these issues by using a larger sample of approximately 4,000 daily short sale transactions for NYSE stocks listed from April 2004 to March 2005 and find conflicting results. Specifically, they find no evidence of a concentration of short interest transactions prior to announcements of bad earnings news. The authors conjecture that the removal of investor access to selective disclosures by Regulation FD may be contributing to the difference between their results and the results of Christophe et al. (2004).

Three concurrent studies provide additional evidence that short positions are associated with earnings information. Akbas et al. (2008) finds that short interest levels are negatively associated with earnings surprises calculated using the most recent quarterly earnings. Francis et al. (2008) find that realized earnings for firms with high levels of unexpected short interest are more likely to fall short of the consensus analyst

\footnotetext{
${ }^{10}$ I extend this line of research in two ways. First, I examine the relation between short interest and earnings levels and changes over the next two quarterly earnings announcements. Second, I test whether the information contained in short interest about future earnings is subsumed by information in analyst earnings forecasts.
} 
forecast before the unexpected increase in short interest. ${ }^{11}$ The authors infer that shortsellers are able to identify firms whose fundamentals the market has over-estimated. Desai et al. (2007) investigate a small sample of 67 firms identified by an independent research firms as potential targets for short-selling. They provide anecdotal evidence that 24 of the 67 firms (or 36\%) reported "lower than expected earnings" during the 12 month period after the independent research firm released its report. ${ }^{12}$

Finally, Pownall and Simko (2005) initiated a new line of short-selling research by examining whether short sellers act as information intermediaries in the capital markets. The authors assert that short-sellers' ex post observable trades are a proxy for their information-processing and forecasting activities. They examine abnormal returns around large increases in short interest (spikes). They find that the average abnormal return for the 5-day period following the public announcement of the short-spike are negative, but "very modest" (10 basis points over 6 trading days) and insignificantly different from zero. ${ }^{13}$ However, when they partition their sample on low analyst following (no more than one analyst) versus high analyst following (more than one analyst), they find negative and economically significant abnormal returns around the 236 short-interest spikes in the low following group (mean $=-1.5 \%$ ) and insignificant positive returns around the 1,441 short-interest spikes in the high following group (mean

\footnotetext{
${ }^{11}$ Francis et al. (2008) use prediction errors from a monthly model of short interest to proxy for unexpected short interest, and use analyst forecast revisions and forecast errors to proxy for the market's expectations of future earnings. Although I use many of the variables employed by Francis et al. (2008) in my analysis, their research question, research design, and inferences differ considerably from mine.

${ }^{12}$ Note that this evidence is based on a small sample of firms identified as potential targets for shortselling and as such, does not reflect the actual investment decisions of short-sellers.

${ }^{13}$ The authors identify the public announcement of the short spike using the disclosure dates reported in the Dow Jones Newswire.
} 
$=0.12 \%)$. Pownall and Simko (2005) also find that abnormal returns for firms with high analyst following are negatively associated with prior earnings levels, which suggests that investors believe short-interest spikes provide information about the sustainability of these firms' earnings. However, Pownall and Simko (2005) do not investigate the extent to which short interest predicts future earnings levels and changes or whether information from analysts subsumes the information in short interest about future earnings. I investigate this relationship in this study.

\subsection{Relevant Literature on Financial Analysts}

A long line of prior research finds that analyst earnings forecasts convey new information to the market. For example, Givoly and Lakonishok (1979) find significant abnormal returns during the four-month period surrounding analyst forecast revisions. Francis and Soffer (1997) examine abnormal returns around analyst stock report publication dates and demonstrate that earnings forecast revisions contain information beyond other information in stock recommendations. Several other studies find evidence of a significant contemporaneous association between analyst forecast revisions and stock price movements (see, e.g., Griffin 1976; Lys and Sohn 1990; Stickel 1991; Gleason and Lee 2003). Furthermore, prior research finds that forecast accuracy is associated with favorable career outcomes, suggesting that forecast accuracy is important to analysts. For example, Stickel (1992) finds that analysts on the Industrial Investor All-American Research Team have more accurate earnings forecasts relative to other analysts. Mikhail et al. (1999) find that analysts with less accurate forecasts are more likely to change brokerage houses, which they label "turnover." They assume that 
turnover of poorer-performing analysts is primarily dominated by terminations, rather than by the analysts seeking a better job. Hong et al. (2000) extend the analyses of Mikhail et al. (1999) by assuming that an analyst is terminated only if the analyst stops producing forecasts for all firms they follow in I/B/E/S. Consistent with Mikhail et al. (1999), they find that less accurate analysts are more likely to be terminated (exit I/B/E/S). Finally, Hong and Kubik (2003) investigate whether analyst forecast accuracy affects job changes within the brokerage firm. They find that analysts whose forecast are more accurate relative to their peers are more likely to be promoted within the brokerage hierarchy and that analysts whose forecasts are less accurate are more likely to be demoted. Overall, this line of research suggests that analysts have incentives to issue accurate forecasts.

Another line of research finds that analyst earnings forecasts are optimistic on average (see, e.g., Abarbanell 1991; Ali et al. 1992; McNichols and O’Brien 1997; Easterwood and Nutt 1999; Richardson et al. 2004). Several studies offer explanations for this optimism. A theoretical model developed in Lim (2001) suggests that rational analysts who aim to improve their earnings forecast accuracy may optimally produce optimistic forecasts. This is because analysts must balance their incentive to issue accurate earnings forecasts with their incentive to maintain positive relationships with firm managers, who are a key source of information about earnings. Consistent with this idea, McNichols and O'Brien (1997) suggest that the observed optimistic-bias in analyst forecasts is partly due to analysts' reluctance to update their forecasts with pessimistic information. Chan et al. (1996) argue that analysts may wait for other analysts to 
respond first to bad news to avoid antagonizing management or that analysts may choose to wait for additional evidence before adjusting their estimates downward. Evidence also suggests that favorable career outcomes are linked to optimistic forecasts. Hong and Kubik (2003) find that analysts who issue relatively optimistic forecasts are more likely to be promoted within the brokerage firm.

A related line of research investigates analyst inefficiency with respect to publicly available information, including prior returns (Abarbanell 1991), earnings (Abarbanell and Bernard 1992), accruals (Bradshaw et al. 2001), and other financial statement items such as inventory and gross margin (Abarbanell and Bushee 1997). This research finds that analysts generally under-react to publicly available information, so that the association between the information and analyst forecast errors is in the same direction as the association between the information and future earnings. ${ }^{14}$ Easterwood and Nutt (1999) find that analysts systematically under-react to bad news. Griffin (2003) examines analyst reactions to earnings restatements and finds limited evidence that analysts reduce their forecasts ahead of such disclosures. However, Griffin (2003) finds strong evidence that the largest forecast revisions occur in the month of the disclosure suggesting that analysts simply react to the news rather than anticipate it. ${ }^{15}$

\footnotetext{
${ }^{14}$ One explanation for the observed analyst inefficiency offered by these papers is that analysts are unable to collect and interpret public signals. This explanation suggests a lack of sophistication on the part of analysts. Another explanation is that analysts only update their forecasts when they obtain new private information about a firm.

${ }^{15}$ Overall, Griffin (2003) concludes that analysts are more reluctant than other sophisticated parties (i.e., insiders, short-sellers, and institutions) to update their publicly observable beliefs to reflect bad news.
} 


\subsection{Motivation}

To summarize, prior research finds that short-sellers are informed investors who have information about the cross-section of future returns. Prior research on financial analysts finds that analyst predictions of earnings provide useful information to the market. It also finds that their forecasts are, on average, optimistically-biased, and are inefficient with respect to available information.

Thus, the literatures on short-sellers and analysts suggest that these two groups are similar in that they both anticipate future performance. Analysts incorporate their predictions in earnings forecasts, while short-sellers trade on their forecasts. Both groups have incentives to anticipate future performance accurately. This raises the question of whether investors can infer incremental information about future performance from each intermediary.

Despite the similarities between short-sellers and analysts, their performance metrics and incentives are different. Short-sellers predict stock returns and must weigh the potential benefits of taking the short position against the accompanying costs and risks. Analysts predict earnings, and must balance incentives to issue accurate forecasts and to maintain relationships with managers (Lim 2001). These differences suggest that short-sellers and analysts may use (i.e., respond to) different information sets and/or use similar information sets differently to make their predictions. If this is the case, investors could infer incremental and complementary information about future earnings and returns from each intermediary. 
Most extant research investigates whether short interest or analyst earnings forecasts in isolation predict future firm performance. ${ }^{16}$ As discussed above, studies in accounting and finance find that short interest predicts future returns (Dechow et al. 2001; Desai et al. 2002; Asquith et al. 2005; Akbas et al. 2008) and future earnings (Christophe et al. 2005; Akbas et al. 2008; Francis et al. 2008). However, these studies do not simultaneously control for analyst earnings forecasts in their models. Controlling for earnings forecasts is important because information contained in short interest about future performance may already be reflected in more readily available information provided by financial analysts. In this study, I simultaneously assess the incremental usefulness of information provided by short-sellers and financial analysts. This approach allows me to address the question of whether these two intermediaries develop complementary information about future performance. The integrated analyses, together with the similarities and differences between short-sellers and analysts discussed above, motivate the empirical predictions that follow.

\subsection{Empirical Predictions}

The information used by short-sellers to predict returns is also likely to predict earnings for two reasons. First, prior studies document that return volatility increases around earnings announcements (Beaver 1968) and that the announcement of bad

\footnotetext{
${ }^{16}$ Several extant studies in finance incorporate variables from financial analyst and short-seller activities into their empirical models. For example, Boehmer and Kelley (2007) find that institutional ownership is negatively associated with stock price efficiency, controlling for short interest and/or analyst following. Danielson and Sorescu (2001) and Boehme et al. (2007) both examine Miller's (1977) hypothesis that dispersion of investor beliefs, in the presence of short-sale constraints, results in stock price overvaluation. These studies use variation in analyst earnings forecast to proxy for the dispersion of investor beliefs. However, these studies do not examine whether short-sellers and analysts develop complementary information about future performance.
} 
earnings news is associated with stock price declines (Brown et al 1987). Thus, shortsellers have incentives to uncover information that helps them anticipate future earnings news. Second, even if short-sellers do not specifically focus on earnings, prior studies find that stock returns and accounting earnings are positively correlated (Kothari 2001) and that some events which affect stock prices are recognized in the accounting system with a lag (Collins et al. 1987). More specifically, Warfield and Wild (1992) state that prices generally lead earnings because an informed market reacts to economic events as they occur, but earnings must wait for compliance with formal accounting recognition criteria. Thus, short-sellers may anticipate events that lead to stock price declines and that are reflected in current or subsequent quarters' earnings.

Incentives to provide accurate forecasts should lead financial analysts to incorporate all available information in their forecasts. However, analyst forecasts may not fully reflect the information in short interest about future earnings (i.e., analysts may under-react to the information) for a variety of reasons. Analysts may share short-sellers beliefs, but choose not to adjust their forecasts either because they are reluctant to damage relationships with management by updating their forecasts with pessimistic information (Francis and Philbrick 1993; McNichols and O'Brien 1997; Lim 2001) or because they are uncertain about the timing of the earnings effect. Analysts may systematically under-react to the earnings information in the RSI ratio, just as they do to the other public signals (Abarbanell 1991; Abarbanell and Bernard 1992; Bradshaw et al. 2001; Abarbanell and Bushee 1997; Easterwood and Nutt 1999). Finally, analysts may view short interest as an unreliable signal about future earnings because they view short- 
sellers as mere story-tellers who do not conduct rigorous fundamental analyses and/or who fabricate bad news about their target-firm in order to drive stock prices down.

This discussion suggests that short interest contains information that is useful for predicting earnings and it is an empirical question whether analyst earnings forecasts fully subsume this information. My first hypothesis is as follows:

\section{H1: The relative short interest ratio contains information that is useful for predicting} earnings beyond the information available in analyst earnings forecasts.

As discussed above, short interest serves as a proxy for short-sellers' predictions of future returns (SEC 1999; Pownall and Simko 2005) and, on average, firms with the highest RSI ratios experience negative future abnormal returns (Asquith and Meulbroek 1996; Dechow et al. 2001; Desai et al. 2002; Asquith et al. 2005). Empirical evidence also suggests that analyst forecasts predict future abnormal returns. For example, Mendenhall (1991) finds a positive association between forecast revisions and abnormal returns around the two subsequent earnings announcements. Stickel (1991) finds that the market assimilates the information in forecast revisions slowly; he documents that stock prices continue to drift in the direction of a revision for up to six months following the revision. Barth and Hutton (2004) find that portfolios formed based on the sign of consensus analyst forecast revisions earn spreads in abnormal returns of 5.5 percent over the next year. ${ }^{17}$

\footnotetext{
${ }^{17}$ Consistent with Barth and Hutton (2004), Chan et al. (1996) also find that portfolios of stocks formed based on past consensus forecast revisions produces significant spreads in abnormal returns over the 6months following the portfolio formation.
} 
These findings suggest that analyst forecast revisions contain information that is useful for predicting future earnings and it is an empirical question whether short interest fully subsumes this information. My second hypothesis is as follows:

H2: Analyst forecast revisions contain information that is useful for predicting abnormal returns beyond the information available in the relative short interest ratio.

Overall, evidence consistent with $H 1$ and $H 2$ would suggest that short-sellers and financial analysts develop complementary information that is useful for predicting earnings and returns. After presenting test related to each hypothesis, I also test whether investors can improve predictions made by one intermediary by incorporating information provided by the other. 


\section{SAMPLE SELECTION, VARIABLE MEASUREMENT, AND DESCRIPTIVE STATISTICS}

\subsection{Sample Selection and Variable Measurement}

My empirical tests require quarterly financial statement data as well as data on short interest, stock returns, and analyst forecasts. I obtain short interest data from a publicly available dataset compiled in machine-readable form from the NYSE, AMEX, and NASDAQ stock exchanges. The dataset reports monthly short interest levels covering the 1988 to 2002 time period. ${ }^{18}$ The stock exchanges compile short interest for individual stocks on the $15^{\text {th }}$ day of each month, or the proceeding business day if the $15^{\text {th }}$ is not a business day. I label this date the short interest measurement date. In general, the NYSE/AMEX exchanges disclose short interest information to the public within the following four business days and the NASDAQ discloses the information within the following eight business days (Jones and Larsen 2004). Consequently, I add four and eight business days to the $15^{\text {th }}$ for the NYSE/AMEX and NASDAQ exchanges respectively, and label this subsequent date the short interest publication date.

Following prior studies (Asquith and Meulbroek 1996; Dechow et al. 2001; Desai et al. 2002; Asquith et al. 2005), I calculate the relative short interest ratio, RSIratio, by dividing the number of shares sold short by the number of shares outstanding. Since I test my predictions in a quarterly setting, I measure the RSIratio as of last month of the fiscal quarter.

\footnotetext{
${ }^{18}$ AMEX short interest data is only available for the 1995 to 2002 period.
} 
I obtain financial statement data from the COMPUSTAT Quarterly database and require that sample observations have data on assets [data44], share price [data14], shares outstanding [data61], and value of book equity [data59] for the prior and current fiscal quarters. I also require the date of the quarterly earnings announcement [RDQE] for the prior, current, and next fiscal quarters. Finally, I remove all observations that report quarter-end stock prices of less than one dollar. ${ }^{19}$

My empirical tests are further restricted to firms with available stock return data obtained from the Center for Research in Security Prices (CRSP) database and with quarterly earnings [EPS] and consensus analyst forecast data obtained from $\mathrm{I} / \mathrm{B} / \mathrm{E} / \mathrm{S}$. In particular, I require that CRSP returns data be available for the period beginning twelvemonths before the prior fiscal quarter-end date and ending six-months after the last consensus analyst forecast preceding the earnings announcement date for the current fiscal quarter. I also require that I/B/E/S quarterly EPS and consensus forecasts data be available for the prior, current, and next fiscal quarters and that the last consensus analyst forecast for the current fiscal quarter occur after the short interest publication date.

Imposing the data requirements detailed above on the intersection of the COMPUSTAT, CRSP, I/B/E/S and short interest databases yields a final sample of 90,427 firm-quarter observations. ${ }^{20}$ Appendix A provides definitions for the variables

\footnotetext{
${ }^{19}$ I apply this restriction to avoid a small-denominator problem in variables scaled by stock price and to focus on economically significant stocks.

${ }^{20}$ To avoid the undue influence of extreme observations, I winsorize all continuous variables, except those related to stock returns, at the top and bottom one percent of their respective distributions.
} 
used in the empirical tests. ${ }^{21}$ Figure 2 reports the relative timing of the key variables and also provides the average number of days between the various variable measurement dates.

\subsection{Descriptive Statistics}

Table 1, Panel A provides descriptive statistics for the primary variables, as well as for the control variables used in the empirical tests. Consistent with prior studies (Asquith and Meulbroek 1996; Dechow et al. 2001), I find that the distribution of the RSIratio is right-skewed, with mean and median shares sold short of $1.9 \%$ and $0.7 \%$ of shares outstanding, respectively. The mean quarterly earnings per share is $0.8 \%$ of stock price and the median is $1.3 \%$ of stock price. The mean consensus analyst forecast error is negative, suggesting that on average analysts are optimistic about future earnings. The mean forecast revision is also negative, suggesting that analysts become more pessimistic as the earnings announcement date approaches. Finally, $18 \%$ of the firms in the sample experience losses.

Due to the large proportion of firms reporting low levels of short interest, I follow Dechow et al. (2001) and partition my sample into two sub-samples based on the magnitude of the RSIratio. I classify all firm-quarter observations with more than $0.5 \%$ of the outstanding shares sold short as "high short interest" firms and all firm-quarter observations with less than $0.5 \%$ of the outstanding shares sold short as "low short interest" firms. Observations in the high short interest sample are further grouped into 10 portfolios based on the rank of the RSIratio in the current fiscal quarter. I label the

\footnotetext{
${ }^{21}$ All per-share data are adjusted for stock splits using the COMPUSTAT adjustment factor [data17].
} 
FIGURE 2

Timing of Variable Measurement



$\overline{\text { Short Int. Measurement }}$ Date is the date that the stock exchanges compile short interest data and generally falls on the $15^{\text {th }}$ day of the month; Short Int. Public. Date is the date that short interest data is released to the public, which generally occurs 4 (8) days after the Short Int. Measurement Date for

NYSE and AMEX (NASDAQ) firms; End Date is the fiscal quarter-end date; RDQE is the report date of quarterly earnings as reported by

COMPUSTAT; Last Analyst Forecast is the date of the last consensus analyst forecast of earnings per share as reported by I/B/E/S; and First Analyst Forecast is the date of the first consensus analyst forecast of earnings per share after the prior quarter's earnings announcement as reported by I/B/E/S. 
TABLE 1

Descriptive Statistics

Panel A: Descriptive statistics for the primary and control variables

Primary Variables

\begin{tabular}{lrrrrr}
\hline & Mean & Std. Dev. & 1st Quartile & Median & 3rd Quartile \\
\hline RSI Ratio & 0.019 & 0.035 & 0.001 & 0.007 & 0.021 \\
EPS & 0.008 & 0.025 & 0.004 & 0.013 & 0.020 \\
LEPS & -0.001 & 0.021 & -0.004 & 0.002 & 0.004 \\
LFEPS & 0.010 & 0.021 & 0.005 & 0.013 & 0.020 \\
FE & -0.001 & 0.010 & -0.001 & 0.000 & 0.002 \\
FREV & -0.002 & 0.007 & -0.001 & 0.000 & 0.000 \\
ABRET6 & 0.008 & 0.414 & -0.218 & -0.031 & 0.163
\end{tabular}

Control Variables

\begin{tabular}{lrrrrr}
\hline & Mean & Std. Dev. & 1st Quartile & Median & 3rd Quartile \\
\hline MVE & 1,507 & 3,907 & 113 & 328 & 1,011 \\
LnMVE & 5.91 & 1.60 & 4.73 & 5.79 & 6.92 \\
BTM & 0.58 & 0.40 & 0.30 & 0.49 & 0.74 \\
LnBTM & -0.78 & 0.72 & -1.20 & -0.71 & -0.30 \\
RET & 0.175 & 0.762 & -0.215 & 0.069 & 0.379 \\
LOSS & 0.18 & 0.38 & 0.00 & 0.00 & 0.00 \\
ANAFOL & 4 & 4 & 2 & 3 & 6
\end{tabular}


TABLE 1 (Continued)

Panel B: Mean and median relative short interest ratios for portfolios formed based on the magnitude of the relative short interest ratio.

\begin{tabular}{|c|c|c|c|c|c|c|c|c|}
\hline & & & \multicolumn{2}{|c|}{ RSI Ratio } & \multicolumn{2}{|c|}{ MVE } & \multicolumn{2}{|c|}{ BTM } \\
\hline $\begin{array}{c}\text { RSI } \\
\text { Port. }\end{array}$ & RSIdec & $\mathbf{N}$ & Mean & Med. & Mean & Med. & Mean & Med. \\
\hline
\end{tabular}

\begin{tabular}{lccccccccc} 
Low & & & & & \\
Short Interest & 0 & 0.0 & 40,039 & 0.002 & 0.001 & 779 & 160 & 0.64 & 0.56 \\
\cline { 2 - 7 } $\begin{array}{l}\text { High } \\
\text { Short Interest }\end{array}$ & 1 & 0.1 & 5,007 & 0.006 & 0.006 & 2,365 & 436 & 0.55 & 0.47 \\
& 2 & 0.2 & 5,041 & 0.008 & 0.008 & 2,803 & 535 & 0.53 & 0.45 \\
& 3 & 0.3 & 5,049 & 0.010 & 0.010 & 2,512 & 586 & 0.52 & 0.45 \\
& 4 & 0.4 & 5,044 & 0.013 & 0.013 & 2,467 & 629 & 0.51 & 0.43 \\
& 5 & 0.5 & 5,034 & 0.017 & 0.016 & 2,173 & 652 & 0.51 & 0.43 \\
& 6 & 0.6 & 5,050 & 0.022 & 0.021 & 2,044 & 643 & 0.51 & 0.42 \\
& 7 & 0.7 & 5,051 & 0.029 & 0.028 & 1,824 & 636 & 0.50 & 0.40 \\
& 8 & 0.8 & 5,042 & 0.040 & 0.039 & 1,678 & 591 & 0.47 & 0.38 \\
& 9 & 0.9 & 5,048 & 0.061 & 0.060 & 1,534 & 540 & 0.47 & 0.35
\end{tabular}

The descriptives statistics are based on 90,427 firm-quarter observations for all variables except $\triangle E P S$, which is based on 71,106 firm-quarter observations. Firm-quarters with less than $0.5 \%$ of outstanding shares sold short are grouped into a single portfolio, labeled the Low Short Interest Sample. Firm-quarters with more than $0.5 \%$ of outstanding shares sold short are included in the High Short Interes Sample and are grouped into ten portfolios, based on the magnitude of the RSIratio. RSIdec is the decile ranking, scaled to range between $[0,1]$.

ranked variable RSIdec. Because the RSI ratios for observations in the low short interest sample exhibit little cross-sectional variation, all observations in this sample are grouped into a single portfolio which takes an RSIdec value of 0 . For the empirical tests, I scale 
$R$ SIdec to range between 0 and 1 (as opposed to 0 and 10). This transformation facilitates the interpretation of the coefficient on RSIdec in the regression analyses. ${ }^{22}$

Table 1, Panel B presents the number of observations for each portfolio of RSIdec and provides the mean and median values for the RSI ratio, the market value of equity, and the book-to-market value ratio across portfolios. In the low short interest sample, the mean RSIratio is $0.2 \%$. In the high short interest sample, the lowest and highest portfolios have a mean RSIratio of $0.6 \%$ and $13.2 \%$, respectively. With respect to the relationship between portfolios of RSI ratios and firm size, I find that firms in the extreme portfolios (i.e., portfolios 0 and 10) are smaller on average than firms in the middle portfolios. However, during the sample period the median firm size in the COMPUSTAT universe is $\$ 178$ million, which is similar to the median firm size of $\$ 160$ million in RSI portfolio 0 and less than the median firm size of $\$ 452$ million in RSI portfolio $10 .^{23}$ This suggests that the extreme portfolios are not primarily composed of small firms. Finally, I find a clear, negative association between the magnitude of the RSI ratio and the book-to-market ratio. This is consistent with evidence presented in Dechow et al. (2001) that short-sellers target firms with relatively low book-to-market ratios (i.e., glamour firms). ${ }^{24}$

\footnotetext{
${ }^{22}$ In untabulated sensitivity tests, I find that the results are not sensitive to this portfolio approach. Specifically, I re-estimate each empirical model using the continuous RSI ratio, and after omitting all low short interest firms or those with firms RSI ratios of zero. I find that all results are qualitatively similar to those reported using the portfolio approach.

${ }^{23}$ I determined the median firm size using all firms in COMPUSTAT from the NYSE, AMEX, and NASDAQ exchanges with stock prices greater than 1 dollar and data available to calculate year-end market value of equity.

${ }^{24}$ I control for size and book-to-market in all of the empirical tests to follow.
} 
Before proceeding to the main empirical models and tests of hypothesis, I investigate the stability of the RSI ratio over time. Table 2, Panel A presents a transition matrix for changes in RSI portfolios between consecutive quarters. For firms in the high short interest sample, I combine the portfolios (effectively creating quintiles) for ease of exposition. The values in the matrix are stated in terms of percentages, such that the sum of the percentages across each row is $100 \%{ }^{25}$ It is evident from examining the concentrations on the diagonal-cells that the tendency is for firms to remain in a similar RSI portfolio over the next quarter. The concentrations within the diagonal-cells are also greater at the extremes. Specifically, more than $70 \%$ of the firms in the lowest and highest two portfolios of RSI ratios remain in the same portfolio in the next quarter. I also find that large changes in RSI ratios occur relatively infrequently. Approximately $1 \%$ of firms move from the highest to the lowest portfolios, and vice versa.

In Table 2, Panel B, I present the transition matrix for RSI portfolio changes twoquarters-ahead. The evidence is consistent with Panel A in that concentrations are observed on the diagonal-cells; however, as would be expected the magnitudes of the concentrations are lower than those reported in Panel A (i.e., changes are more likely as the change horizon increases).

\footnotetext{
${ }^{25}$ To illustrate, cell $(0,0)$ can be interpreted as follows: $78 \%$ of the firms in the lowest short interest portfolio in quarter $\mathrm{t}$, remain in the lowest short interest portfolio in quarter $\mathrm{t}+1$.
} 


\section{TABLE 2}

\section{Transition Matrix for Changes in Short Interest Portfolio Membership over the Next Two Quarters}

Panel A: Percentage of instances when a firm changes RSI portfolio membership between the current quarter and next quarter.



Panel B: Percentage of instances when a firm changes RSI portfolio membership between the current quarter and two-quarters-ahead.



RSI Porfolios of the high short interest sample are combined for parsimony. The sum of the percentages across each row is $100 \%$. 
Overall, the results presented in Table 2 suggest that extreme magnitudes of short interest (either high or low) are fairly stable over time and that large changes in short interest are relatively rare. This is relevant for investors and for my empirical tests because it suggests that short-sellers' expectations of low returns that are implicit in high RSI ratios do not dissipate over just one fiscal quarter. 


\section{EMPIRICAL MODELS AND RESULTS}

In this section, I present the empirical models, main hypothesis tests, and tests of practical implications of my analysis for investors. Each of the regression models described below is estimated by fiscal-quarter using the Fama and MacBeth (1973) estimation procedure to control for cross-sectional correlation. ${ }^{26}$ I assess the statistical significance of the associations using $t$-tests based on the time-series means and standard errors from the quarterly regressions. I also report the number of times the coefficient in the quarterly regressions is positive or negative and calculate a one-way $\chi^{2}$ statistic to test the observed percentage of positive or negative coefficients (depending on the predicted sign) against the null hypothesis that the percentage is equal to $50 \%$.

\subsection{The Incremental Information Content of Short Interest for Future Earnings beyond}

\section{Analyst Forecasts}

In this section of the dissertation, I address my first research question by investigating whether information in short interest is useful for predicting future earnings beyond the information available in analyst earnings forecasts.

\subsubsection{Univariate Tests}

I begin by examining future accounting profitability measures across RSI ratio portfolios. I plot this relation in Figure 3, and find that quarter-one earnings per share levels decrease nearly monotonically across the portfolios. The results for the

\footnotetext{
${ }^{26}$ Another potential concern is time-series correlation resulting from a firm-effect. As a robustness test, I re-estimate the models and compute Roger's standard errors (Rogers 1993), allowing the residuals to cluster by firm. All results (untabulated) are qualitatively similar to the Fama and MacBeth (1973) estimation results reported in the tables.
} 
FIGURE 3

Mean and Median Future Accounting Profitability across Relative Short Interest Ratio Portfolios
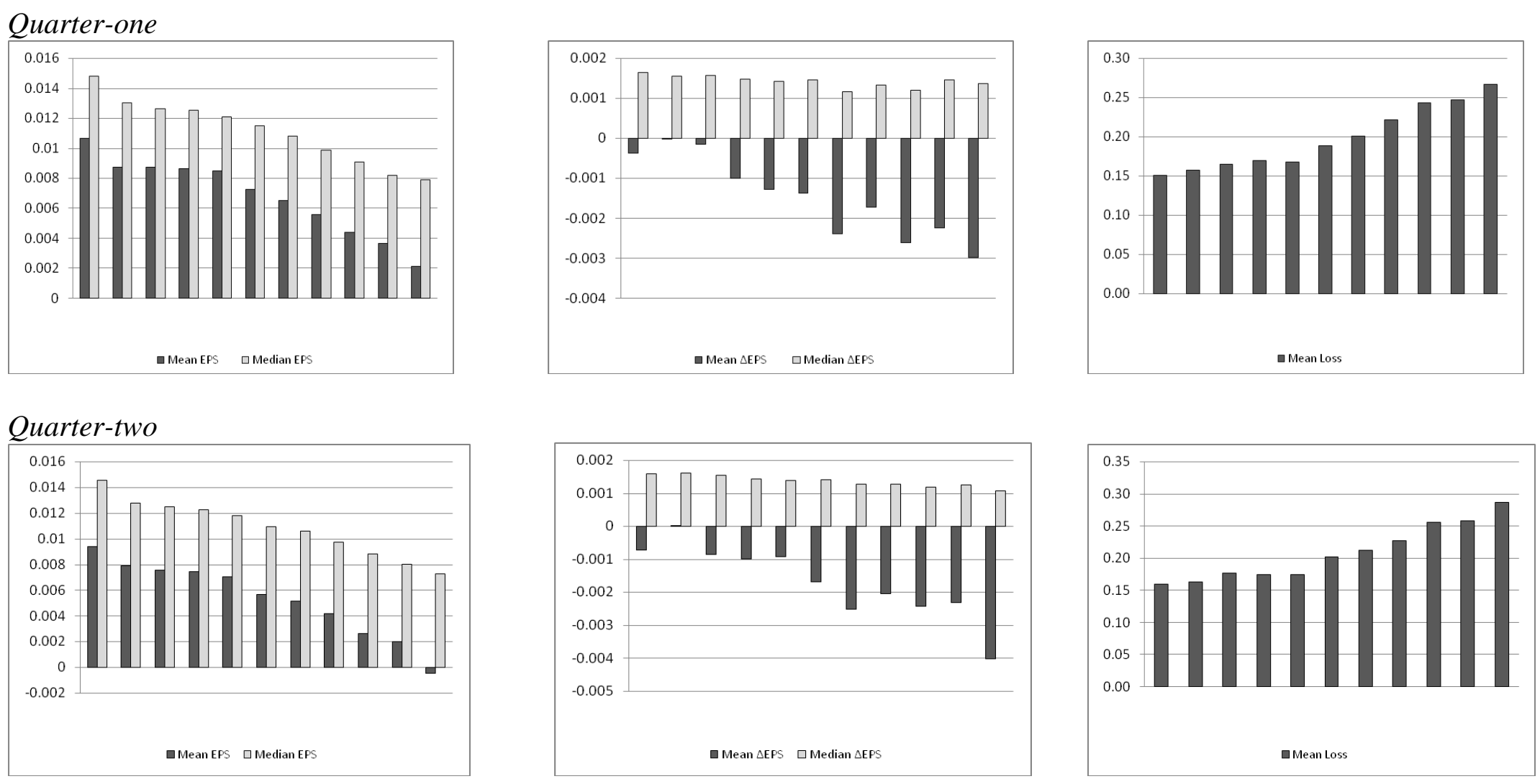

Firm-quarters with less than $0.5 \%$ of outstanding shares sold short are grouped into portfolio 0 . Firm-quarters with more than $0.5 \%$ of outstanding shares sold short are grouped into portfolios $1-10$ based on the magnitude of the RSIratio. 
quarter-one change in earnings per share are mixed. The median change in earnings per share is positive in each portfolio and the magnitudes are relatively stable across the portfolios. However, the mean change in earnings per share is negative in all but one portfolio, and generally becomes more negative across the relative short interest portfolios. Figure 3 also reveals that firms with high RSIratios have a greater incidence of losses in quarter-one than firms with low RSIratios. The results for quarter-two earnings per share, changes in earnings per share, and losses are qualitatively similar to the results for quarter-one. Together, these results provide preliminary evidence that the RSIratio is negatively associated with accounting profitability realized over the next two fiscal quarters.

\subsubsection{Multivariate Tests Using Quarter-one Earnings}

In this sub-section, I investigate the association between RSIdec and earnings levels or changes after controlling for the information in the last consensus analyst forecast of earnings and various other control variables. I examine earnings levels to investigate whether short interest contains information about the cross-section of future accounting profitability. That is, I test whether higher (lower) levels of short interest are associated with lower (higher) future earnings performance. However, differences in earnings performance across levels of short interest might be long-standing; thus, I also examine whether levels of short interest are negatively associated with future earnings changes. This test allows me to infer whether short interest contains information about future earnings innovations. Specifically, I estimate the following models in quarterone: 


$$
\begin{aligned}
& E_{P S}=\beta_{0}+\beta_{1} \text { RSIdec }_{t}+\beta_{2} \operatorname{EPS}_{t-1}+\beta_{3} \operatorname{RET}_{t-1}+\beta_{4} \operatorname{LnMVE}_{t-1}+\beta_{5} \operatorname{LnBTM}_{t-1} \\
& +\beta_{6} \text { LFEPS }_{t}+\varepsilon \\
& \text { and } \\
& \Delta E P S_{t}=\delta_{0}+\delta_{1} \text { RSIdec }_{t}+\delta_{2} \Delta E P S_{t-1}+\delta_{3} R_{E T} T_{t-1}+\delta_{4} \operatorname{LnMVE}_{t-1}+\delta_{5} \operatorname{LnBTM}_{t-1} \\
& +\delta_{6} L F \Delta E P S_{t}+\varepsilon \text {, }
\end{aligned}
$$

where:

$t=\quad$ Quarter indicator;

$E P S=\quad$ Quarterly earnings per share as reported by $\mathrm{I} / \mathrm{B} / \mathrm{E} / \mathrm{S}$, scaled by the stock price at the beginning of the quarter [COMPUSTAT data14];

$\triangle E P S=\quad$ Seasonal change in quarterly earnings per share, measured as earnings in the current less earnings in the same quarter one year prior, scaled by the stock price at the beginning of the quarter;

RSIdec $=\quad$ Decile ranking of the relative short interest ratio (number of shares sold short / number of shares outstanding) for the last month in the quarter. For firms with less than $0.5 \%$ of the outstanding shares sold short, RSIdec is set equal to 0 . Firms with more than $0.5 \%$ of the outstanding shares sold short are grouped into deciles based on the magnitude of the RSIratio. RSIdec is scaled to range between $[0,1]$;

$R E T=\quad$ Raw buy-and-hold return measured as the realized monthly return cumulated over the twelve-month period ending on the quarter-end date;

$L n M V E=\quad$ Natural log of the market value of equity [COMPUSTAT data14 $\mathrm{x}$ COMPUSTAT data61];

LnBTM = Natural log of the book-to-market ratio [COMPUSTAT data59 / (COMPUSTAT data14 x COMPUSTAT data61)];

LFEPS $=\quad$ Last consensus analyst forecast for quarterly earnings per share as reported by $\mathrm{I} / \mathrm{B} / \mathrm{E} / \mathrm{S}$, scaled by the beginning of quarter stock price [COMPUSTAT data14]; and

$L F \triangle E P S=\quad$ Last consensus analyst forecast for quarterly earnings per share as reported by $\mathrm{I} / \mathrm{B} / \mathrm{E} / \mathrm{S}$ less earnings per share in the same quarter one year prior, scaled by the beginning of quarter stock price [COMPUSTAT data14]. 
In models (1) and (2), I test whether short interest is negatively associated with earnings levels and changes $\left(\beta_{1}<0\right.$ and that $\delta_{1}<0$, respectively). Significantly negative coefficients on RSIdec would be consistent with $H 1$ and indicate that the relative short interest ratio contains information that is useful for predicting earnings, beyond the information available in the analyst earnings forecast. I control for the information in prior period earnings about quarter-one earnings by including lagged EPS and lagged $\triangle E P S$ as independent variables in models (1) and (2) respectively. I control for the information in prior returns about earnings by including the buy-and-hold raw stock return for a one-year period ending in the prior quarter.

The market value of equity (size) and the book-to-market ratio are included as control variables for two reasons. First, prior studies find that short-sellers target large firms with low book-to-market ratios (i.e., glamour firms) (Dechow et al. 2001; Desai et al. 2007). Therefore, it is important to control for these variables to rule out the possibility that my variable of interest, RSIdec, is merely acting as a proxy for size and/or book-to-market. Second, prior studies find that size and book-to-market ratios are systematically related to future profitability (Fama and French 1995). Thus, the exclusion of these control variables would result in a correlated omitted variables problem. Finally, I control for analyst' earnings forecasts by including the last consensus analyst earnings forecast before earnings are announced as an independent variable in model (1) and by including the forecasted seasonal change in earnings implied by the last consensus analyst earnings forecast as an independent variable in model (2). 
Table 3 presents estimation results for models (1) and (2) in quarter-one. In Panel A, I report results without analyst forecasts in the model so that I can investigate whether the coefficient on RSIdec changes (i.e., is the information in RSI ratios subsumed?) when analyst forecasts are entered into the model. In model (1) the mean coefficient on RSIdec is negative and statistically significant $\left(\beta_{1}=-0.0038 ; p\right.$-value $<$ 0.01). In addition, I find that the coefficient on RSIdec is negative in 60 of the 61 quarterly regressions. This allows rejection of the null hypothesis that the percentage of negative coefficients is $50 \%\left(\chi^{2}=57.07 ; p\right.$-value $\left.<0.01\right)$. The magnitude of the coefficient on RSIdec provides an indication of the economic significance of the results. Recall that RSIdec is scaled to range between zero (firms with the lowest relative short interest ratios) and one (firms with the highest short interest ratios) and that the dependent variable, $E P S_{t}$, is scaled by stock price. Thus, on average, earnings per share is lower by $0.38 \%$ of stock price for the firms with the highest RSI ratios relative to firms with the lowest RSI ratios. If I assume a stock price of \$20, this percentage represents a $\$ 0.076$ difference in earnings per share. This difference in earnings per share is economically significant given that earnings per share as a percentage of stock price for the median firm in the sample is $1.30 \%$ (see Table 1, Panel A), which at a stock price of \$20 implies median earnings of \$0.26. I also find that prior-period earnings, returns, and lagged firm size are all positively and significantly associated with quarterone earnings levels. 


\section{TABLE 3}

The Association between Short Interest and Quarter-One Earnings with and without Controlling for Analyst Forecasts

Model (1): $E_{P S}=\beta_{0}+\beta_{1} \operatorname{RSIdec}_{t}+\beta_{2} \operatorname{EPS}_{t-1}+\beta_{3} \operatorname{RET}_{t-1}+\beta_{4} \operatorname{LnMVE}_{t-1}+\beta_{5} \operatorname{LnBTM}_{t-1}+\beta_{6} \operatorname{LFEPS}_{t}+\varepsilon$

Model (2): $\triangle E P S_{t}=\delta_{0}+\delta_{1}$ RSIdec $_{t}+\delta_{2} \Delta E P S_{t-1}+\delta_{3}$ RET $_{t-1}+\delta_{4} \operatorname{LnMVE}_{t-1}+\delta_{5} \operatorname{LnBTM}_{t-1}+\delta_{6}$ LFAEPS $_{t}+\varepsilon$

Panel A: Without Controlling for Analyst Forecasts

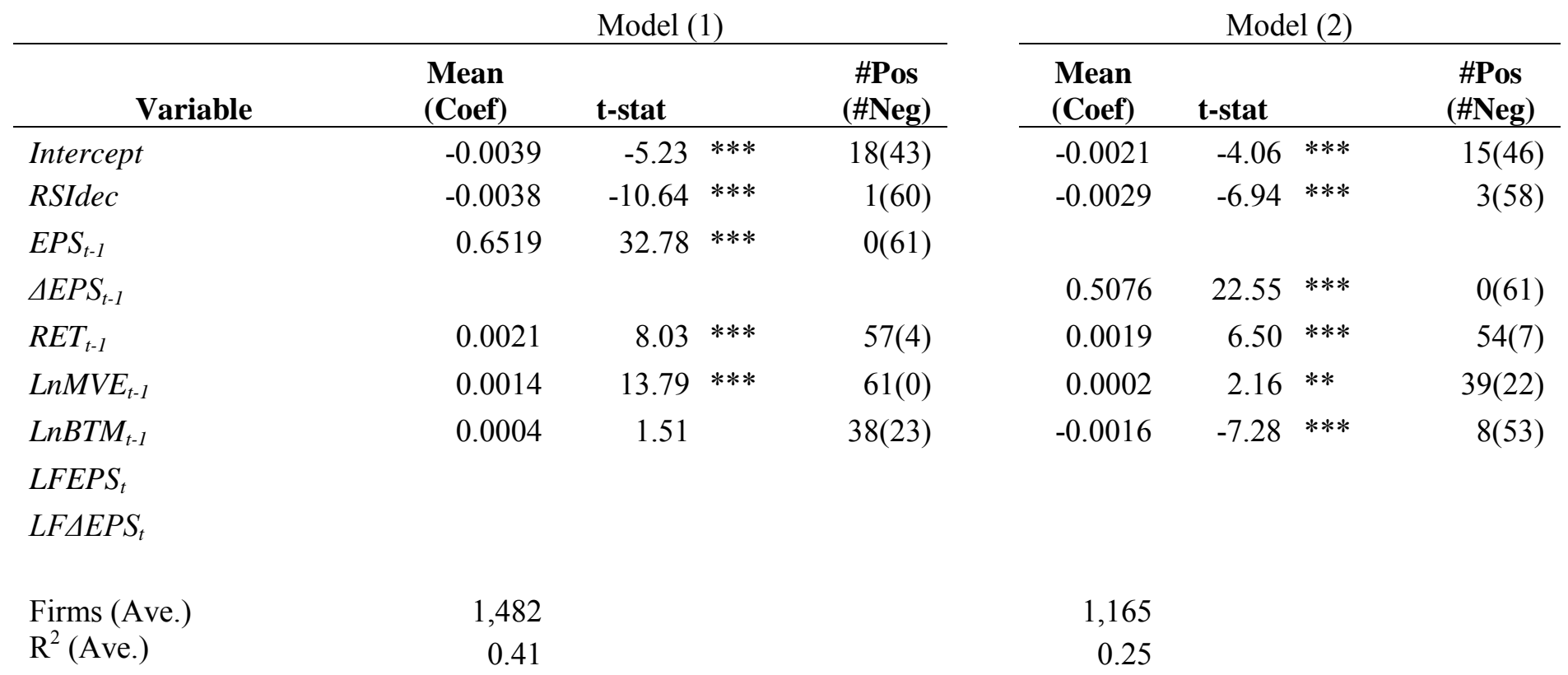




\section{TABLE 3 (Continued)}

Panel B: With Controlling for Analyst Forecasts

\begin{tabular}{|c|c|c|c|c|c|c|c|c|}
\hline \multirow[b]{2}{*}{ Variable } & \multicolumn{4}{|c|}{ Model (1) } & \multicolumn{4}{|c|}{ Model (2) } \\
\hline & $\begin{array}{l}\text { Mean } \\
\text { (Coef) }\end{array}$ & t-stat & & $\begin{array}{c}\text { \#Pos } \\
\text { (\#Neg) }\end{array}$ & $\begin{array}{l}\text { Mean } \\
\text { (Coef) }\end{array}$ & t-stat & & $\begin{array}{c}\text { \#Pos } \\
\text { (\#Neg) }\end{array}$ \\
\hline Intercept & -0.0069 & -15.24 & $* * *$ & $0(61)$ & -0.0056 & -11.56 & $* * *$ & $2(59)$ \\
\hline RSIdec & -0.0012 & -3.98 & $* * *$ & $17(44)$ & -0.0016 & -5.94 & $* * *$ & $10(51)$ \\
\hline$E P S_{t-1}$ & 0.1214 & 11.64 & $* * *$ & $60(1)$ & & & & \\
\hline$\triangle E P S_{t-1}$ & & & & & 0.1138 & 13.28 & $* * *$ & $58(3)$ \\
\hline$R E T_{t-1}$ & 0.0010 & 6.28 & $* * *$ & $50(11)$ & 0.0015 & 5.89 & $* * *$ & $52(9)$ \\
\hline$L n M V E_{t-1}$ & 0.0006 & 13.91 & $* * *$ & $59(2)$ & 0.0006 & 11.34 & $* * *$ & $58(3)$ \\
\hline $\operatorname{LnBTM}_{t-1}$ & -0.0017 & -7.60 & $* * *$ & $6(55)$ & -0.0010 & -5.54 & $* * *$ & $12(49)$ \\
\hline LFEPS $_{t}$ & 0.9554 & 79.70 & $* * *$ & $61(0)$ & & & & \\
\hline$L F \triangle E P S_{t}$ & & & & & 0.9070 & 97.84 & $* * *$ & $61(0)$ \\
\hline Firms (Ave.) & 1,482 & & & & 1,165 & & & \\
\hline $\mathrm{R}^{2}$ (Ave.) & 0.73 & & & & 0.70 & & & \\
\hline
\end{tabular}

*,**,*** indicates significant at the $p<0.10,0.05,0.01$ level respectively. See Appendix A for variable definitions. The number of firms and $\mathrm{R}^{2}$ reported are the averages across the quarterly cross-sectional regressions. 
The results are similar when the change in earnings is the dependent variable (Panel A, model (2)). The mean coefficient on RSIdec is negative and statistical significant $\left(\delta_{1}=-0.0029 ; p\right.$-value $\left.<0.01\right)$ and is negative in 58 of the 61 quarterly regressions $\left(\chi^{2}=49.59 ; p\right.$-value $\left.<0.01\right)$. This suggests that on average, the change in earnings per share is lower by $0.29 \%$ of stock price for the firms with the highest RSI ratios relative to firms with the lowest RSI ratios. At an assumed stocked price of $\$ 20$, this percentage implies that the change in earnings per share is $\$ 0.058$ lower, which is economically significant given that, at a stock price of $\$ 20$, the median firm reports an implied change in earnings per share of $\$ 0.04$.

Next, I re-estimate models (1) and (2) controlling for the information in analyst forecast. Table 3, Panel B presents the estimation results. Consistent with $H 1$, the RSIdec coefficient in model (1) remains negative and statistically significant $\left(\beta_{1}=\right.$ $0.0012 ; p$-value $<0.01$ ) and the coefficient is negative in 44 of the 61 quarterly regressions $\left(\chi^{2}=11.95 ; p\right.$-value $\left.<0.01\right)$. However, the magnitude of the negative coefficient on RSIdec when the consensus analyst forecast is included as a control $\left(\beta_{1}=\right.$ 0.0012), is less than half as large as the magnitude of the negative coefficient on RSIdec when the consensus analyst forecast is excluded as a control $\left(\beta_{1}=-0.0038\right)$. This reduction in the magnitude of the coefficient suggests that some, but not all, of the information in the relative short interest ratio is reflected in the consensus analyst forecast.

In Panel B, model (2), I find that the mean coefficient on RSIdec is negative and statistical significant $\left(\delta_{1}=-0.0016 ; p\right.$-value $\left.<0.01\right)$ and the coefficient is negative in 51 
of the 61 quarterly regressions $\left(\chi^{2}=27.56\right.$; $p$-value $\left.<0.01\right)$, which is consistent with $H 1$. The magnitude of the negative coefficient on RSIdec in model (2), after controlling for analyst forecasts, is less than the magnitude of the negative coefficient on RSIdec in model (2) which does not control for analyst forecasts (see Panel A).

In untabulated tests, I also find that the average coefficient on $R \operatorname{SIdec}\left(\delta_{1}=-\right.$ 0.0016) in Model (2), which explains earnings changes, is significantly greater than the average coefficient on $R$ SIdec $\left(\beta_{1}=-0.0012\right)$ in Model (1), which explains earnings levels. This suggests that short interest levels contain substantial information about earnings innovations.

\subsubsection{Multivariate Tests Using Quarter-two Earnings}

Prior literature finds that changes in prices generally lead changes in earnings (Collins et al. 1987; Warfield and Wild 1992). In this sub-section, I investigate whether the association between RSI ratios and earnings extends to longer earnings horizon (i.e., two earnings announcements ahead), by estimating the following models using quartertwo earnings:

$$
\begin{aligned}
& E P S_{t+1}=\lambda_{0}+\lambda_{1} \text { RSIdec }_{t}+\lambda_{2} \text { EPS }_{t}+\lambda_{3} \text { RET }_{t}+\lambda_{4} \operatorname{LnMVE}_{t}+\lambda_{5} \text { LnBTM }_{t} \\
& +\lambda_{6} \text { LFEPS }_{t+1}+\varepsilon \\
& \text { and } \\
& \Delta E P S_{t+1}=\alpha_{0}+\alpha_{1} \text { RSIdec }_{t}+\alpha_{2} \Delta E P S_{t}+\alpha_{3} R_{E T}+\alpha_{4} \text { LnMVE }_{t}+\alpha_{5} \text { LnBTM }_{t} \\
& +\alpha_{6} L_{F \Delta E P S_{t+1}}+\varepsilon \text {, }
\end{aligned}
$$

where all variables and subscripts are defined previously.

In models (3) and (4), I test whether short interest is negatively associated with quarter-two earnings levels and changes $\left(\lambda_{1}<0\right.$ and $\alpha_{1}<0$ respectively). Table 4 , Panels 
A and B presents the estimation results of models (3) and (4) with and without controls for analyst forecasts. In all models I find that RSIdec is negatively and significantly associated with quarter-two earnings regardless of whether analyst forecast information is included in the model. Consistent with $H 1$, in Panel $\mathrm{B}$, I find that RSIdec is negatively and significantly associated with quarter-two earnings levels $\left(\lambda_{1}=-0.0011 ; p\right.$-value $<$ $0.01)$ and changes $\left(\alpha_{1}=-0.0014 ; p\right.$-value $\left.<0.01\right)$, controlling for information from analysts. The percentage of negative coefficients on RSIdec is also significantly different than $50 \%$ for both models.

The estimation results reported in Tables 3 and 4 reveal that the magnitudes of the coefficients on RSIdec using quarter-one earnings (models (1) and (2)) are similar to the magnitudes of the coefficient on RSIdec using quarter-two earnings (models (3) and (4)). In untabulated tests, I find that the average coefficient on the RSI ratio in model (1) of -0.0012 (reported in Table 3, Panel B) using quarter-one earnings levels is not significantly different than the average coefficient on the RSI ratio in model (3) of 0.0011 (reported in Table 4, Panel B) using quarter-two earnings levels. Similarly, I find that the average coefficient on the RSI ratio in model (2) of -0.0016 (reported in Table 3 , Panel B) using quarter-one earnings changes is not significantly different than the average coefficient on the RSI ratio in model (4) of - 0.0014 (reported in Table 4, Panel B) using quarter-two earnings changes. 


\title{
TABLE 4
}

The Association between Short Interest and Quarter-Two Earnings with and without Controlling for Analyst Forecasts

\begin{abstract}
Model (3): EPS $_{t+1}=\lambda_{0}+\lambda_{1}$ RSIdec $_{t}+\lambda_{2}$ EPS $_{t}+\lambda_{3}$ RET $_{t}+\lambda_{4} \operatorname{LnMVE}_{t}+\lambda_{5} \operatorname{LnBTM}_{t}+\lambda_{6}$ LFEPS $_{t+1}+\varepsilon$
Model (4): $\triangle E P S_{t+1}=\alpha_{0}+\alpha_{1}$ RSIdec $_{t}+\alpha_{2} \Delta E P S_{t}+\alpha_{3}$ RET $_{t}+\alpha_{4} \operatorname{LnMVE}_{t}+\alpha_{5} \operatorname{LnBTM}_{t}+\alpha_{6} \operatorname{LF\Delta EPS}_{t+1}+\varepsilon$
\end{abstract}

Panel A: Without Controlling for Analyst Forecasts






\section{TABLE 4 (Continued)}

Panel B: With Controlling for Analyst Forecasts

\begin{tabular}{|c|c|c|c|c|c|c|c|c|}
\hline \multirow[b]{2}{*}{ Variable } & \multicolumn{4}{|c|}{ Model (3) } & \multicolumn{4}{|c|}{ Model (4) } \\
\hline & $\begin{array}{l}\text { Mean } \\
\text { (Coef) }\end{array}$ & t-stat & & $\begin{array}{c}\text { \#Pos } \\
\text { (\#Neg) }\end{array}$ & $\begin{array}{l}\text { Mean } \\
\text { (Coef) }\end{array}$ & t-stat & & $\begin{array}{c}\text { \#Pos } \\
\text { (\#Neg) }\end{array}$ \\
\hline Intercept & -0.0096 & -15.02 & $* * *$ & $0(61)$ & -0.0075 & -13.68 & $* * *$ & $1(60)$ \\
\hline RSIdec & -0.0011 & -3.82 & $* * *$ & $19(42)$ & -0.0014 & -4.35 & $* * *$ & $10(51)$ \\
\hline$E P S_{t-1}$ & 0.1704 & 14.29 & $* * *$ & $60(1)$ & & & & \\
\hline$\triangle E P S_{t-1}$ & & & & & 0.1477 & 11.80 & $* * *$ & $60(1)$ \\
\hline$R E T_{t-1}$ & 0.0015 & 5.86 & $* * *$ & $53(8)$ & 0.0018 & 6.07 & $* * *$ & $56(5)$ \\
\hline$L n M V E_{t-1}$ & 0.0009 & 14.05 & $* * *$ & $61(0)$ & 0.0009 & 12.78 & $* * *$ & $59(2)$ \\
\hline $\operatorname{LnBTM}_{t-1}$ & -0.0021 & -8.84 & $* * *$ & $2(59)$ & -0.0012 & -6.35 & $* * *$ & $11(50)$ \\
\hline LFEPS $_{t}$ & 0.9255 & 87.52 & $* * *$ & $61(0)$ & & & & \\
\hline$L F \triangle E P S_{t}$ & & & & & 0.8674 & 72.12 & $* * *$ & $61(0)$ \\
\hline Firms (Ave.) & 1,482 & & & & 1,165 & & & \\
\hline $\mathrm{R}^{2}$ (Ave.) & 0.70 & & & & 0.65 & & & \\
\hline
\end{tabular}

*,**,*** indicates significant at the $p<0.10,0.05,0.01$ level respectively. See Table 1 for variable definitions. The number of firms and $\mathrm{R}^{2}$ reported are the averages across the quarterly cross-sectional regressions. 
Thus, I find evidence that the association between short interest and earnings extends up to two earnings announcements ahead, and appears to be unchanged as the earnings horizon is extended by one quarter. This suggests that short interest levels reflect information that is gradually realized in earnings over multiple reporting periods.

In sum, the results presented in Tables 3 and 4 are consistent with $H 1$. They suggest that the relative short interest ratio contains information about earnings realized over the next two quarterly earnings announcements and that the consensus analyst reflects some, but not all, of this information.

\subsection{Assessing Analyst Efficiency with Respect to Short Interest}

\subsubsection{Tests of the Association between Short Interest and Analyst Forecast Errors}

In this sub-section, I examine the association between short interest and quarterone or quarter-two analyst forecast errors. The models presented next follow a long line of empirical research that examines analyst efficiency with respect to an available signal by estimating the association between the publicly available signal and subsequent analyst forecast errors (e.g., Abarbanell 1991; Abarbanell and Bernard 1992;

Mendenhall 1991; Bradshaw et al. 2001). I estimate the following models:

$$
\begin{aligned}
F E_{t}=\psi_{0}+ & \psi_{1} \text { RSIdec }_{t}+\psi_{2} \text { EPS }_{t-1}+\psi_{3} \text { RET }_{t-1}+\psi_{4} \text { LnMVE }_{t-1}+\psi_{5} \operatorname{LnBTM}_{t-1} \\
& +\psi_{6} \operatorname{LOSS}_{t-1}+\varepsilon \\
& \text { and } \\
F_{t+1}=\varphi_{0} & +\varphi_{1} \text { RSIdec }_{t}+\varphi_{2} \text { EPS }_{t}+\varphi_{3} \text { RET }_{t}+\varphi_{4} \text { LnMVE }_{t}+\varphi_{5} \text { LnBTM }_{t} \\
& +\varphi_{6} \text { LOSS }_{t}+\varepsilon
\end{aligned}
$$

where: 
$F E=\quad$ Analyst forecast error measured as EPS minus LFEPS, scaled by the beginning of quarter stock price [COMPUSTAT data14];

$L O S S=\quad$ Indicator variable set equal to one if quarterly earnings per share as reported by $\mathrm{I} / \mathrm{B} / \mathrm{E} / \mathrm{S}$ is negative, and zero otherwise; and

All other variables and subscripts as defined previously.

Models (5) and (6) investigate whether analyst forecasts fully reflect the information in short interest about future earnings. ${ }^{27}$ Specifically, in models (5) and (6), I test whether short interest is negatively associated with quarter-one and quarter-two analyst forecast errors $\left(\psi_{1}<0\right.$ and $\varphi_{1}<0$ respectively). A significantly negative coefficient on RSIdec in models (5) and (6) is consistent with an under-reaction to the information in RSIdec about future earnings. Given that prior studies find that analysts under-react to the information in prior period earnings (Abarbanell and Bernard 1992) and prior period returns (Abarbanell 1991), I include those variables as controls. ${ }^{28}$ I also follow prior studies and control for other known determinants of analyst forecast errors. Specifically, I include firm size to control for the firm's information environment (Das et

\footnotetext{
${ }^{27}$ Since the dependent variable in models (5) and (6) is also a proxy for the earnings surprise, an alternative interpretation is that these models investigate whether short-sellers take positions in firms they expect to miss analyst earnings targets. While my tests cannot rule out this possibility, my research design does require that the short interest information to be publicly available at the time the consensus analyst recommendation is measured. On average, the short interest publication date is 25 days prior to the consensus analyst forecast date and 38 days prior to the earnings announcement (see Figure 2). Therefore, analysts can observe the signal from the short-sellers and respond to that signal if they so choose. Also, if short-sellers are primarily targeting firms they expect to miss analyst targets, it seems unlikely that they would take those positions (and assume the risk) so far in advance of the earnings announcement, especially since analysts revise their forecasts during this period.

${ }^{28}$ Consistent with the prior studies cited, I expect the coefficient on EPS and RET to both be positive, which would suggest that analysts under-react to these information sources.
} 
al. 1998; Eames and Glover 2003), book-to-market to control for growth opportunities (Richardson et al. 2004), and prior-period losses (Ali et al. 1992). ${ }^{29}$

Table 5, Panels A and B present the estimation results of model (5) and (6). In Panel A, the mean coefficient on RSIdec in model (5) is negative and statistically significant $\left(\psi_{1}=-0.0008 ; p\right.$-value $\left.<0.01\right)$. I find that the coefficient on RSIdec is negative in 45 of the 61 quarterly regressions $\left(\chi^{2}=13.79 ; p\right.$-value $\left.<0.01\right)$. The magnitude of the coefficient suggests that, on average, the quarter-one analyst forecast error is lower by $0.08 \%$ of stock price for firms with the highest RSI ratio relative to firms with the lowest RSI ratio. At an assumed stock price of $\$ 20$, this percentage implies that the forecast error is $\$ 0.016$ lower. I also find that each of the control variables is associated with the quarter-one analyst forecast errors in the predicted direction.

In Table 5, Panel B, the mean coefficient on RSIdec in model (6) is also negative and statistically significant $\left(\varphi_{1}=-0.0007 ; p\right.$-value $\left.<0.01\right)$. I find that the coefficient on RSIdec is negative in 55 of the 61 quarterly regressions $\left(\chi^{2}=39.36 ; p\right.$-value $\left.<0.01\right)$.

\footnotetext{
${ }^{29}$ Consistent with prior studies cited, I expect the coefficient on LnMVE to be positive because a higher quality information environment implies smaller (less negative) forecast errors. I expect the coefficient on LnBTM to be negative because, on average, analysts are more optimistic about high book-to-market firms. I expect the coefficient on LOSS because, on average, analysts are more optimistic about loss firms relative to profit firms.
} 
TABLE 5

The Association between Short Interest and Quarter-One and Quarter-Two Forecast Errors

Panel A: Regression results for quarter-one forecast errors

Model (5): $F E_{t}=\psi_{0}+\psi_{1}$ RSIdec $_{t}+\psi_{2}$ EPS $_{t-1}+\psi_{3}$ RET $_{t-1}+\psi_{4} \operatorname{LnMVE}_{t-1}+\psi_{5} \operatorname{LnBTM}_{t-1}+\psi_{6} \operatorname{LOSS}_{t-1}+\varepsilon$

Model (7): $F E_{t}=\psi_{0}+\psi_{1} \operatorname{RSIdec}_{t}+\psi_{2} \operatorname{EPS}_{t-1}+\psi_{3} \operatorname{RET}_{t-1}+\psi_{4} \operatorname{LnMVE}_{t-1}+\psi_{5} \operatorname{LnBTM}_{t-1}+\psi_{6} \operatorname{LOSS}_{t-1}$

$+\psi_{7} H I G H A F_{t}+\psi_{8}\left(\right.$ RSIdec $\left._{t} x H I G H A F_{t}\right)+\varepsilon$

\begin{tabular}{|c|c|c|c|c|c|c|c|c|}
\hline & \multicolumn{4}{|c|}{ Model (5) } & \multicolumn{4}{|c|}{ Model (7) } \\
\hline Variable & $\begin{array}{l}\text { Mean } \\
\text { (Coef) }\end{array}$ & t-stat & & $\begin{array}{c}\text { \#Pos } \\
\text { (\#Neg) }\end{array}$ & $\begin{array}{l}\text { Mean } \\
\text { (Coef) }\end{array}$ & t-stat & & $\begin{array}{c}\text { \#Pos } \\
\text { (\#Neg) }\end{array}$ \\
\hline Intercept & -0.0060 & -14.65 & $* * *$ & $1(60)$ & -0.0059 & -13.47 & $* * *$ & $3(58)$ \\
\hline RSIdec & -0.0008 & -4.01 & $* * *$ & $16(45)$ & -0.0012 & -4.28 & $* * *$ & $17(44)$ \\
\hline$E P S_{t-1}$ & 0.0704 & 13.28 & $* * *$ & $58(3)$ & 0.0705 & 13.38 & $* * *$ & $58(3)$ \\
\hline$R E T_{t-1}$ & 0.0009 & 6.91 & $* * *$ & $51(10)$ & 0.0009 & 7.16 & $* * *$ & $52(9)$ \\
\hline$L n M V E_{t-1}$ & 0.0005 & 12.82 & $* * *$ & $58(3)$ & 0.0005 & 9.26 & $* * *$ & $56(5)$ \\
\hline $\operatorname{LnBTM}_{t-1}$ & -0.0014 & -8.89 & $* * *$ & $4(57)$ & -0.0014 & -8.82 & $* * *$ & $3(58)$ \\
\hline $\operatorname{LOSS}_{t-1}$ & -0.0004 & -1.51 & & $29(32)$ & -0.0004 & -1.42 & & $32(29)$ \\
\hline$H I G H A F_{t}$ & & & & & 0.0001 & 0.75 & & $27(34)$ \\
\hline RSIdec $x \mathrm{HIGHAF}_{t}$ & & & & & 0.0007 & 2.42 & $* *$ & $41(20)$ \\
\hline Firms (Ave.) & 1,482 & & & & 1,482 & & & \\
\hline $\mathrm{R}^{2}$ (Ave.) & 0.06 & & & & 0.06 & & & \\
\hline
\end{tabular}




\section{TABLE 5 (Continued)}

Panel B: Regression results for quarter-two forecast errors

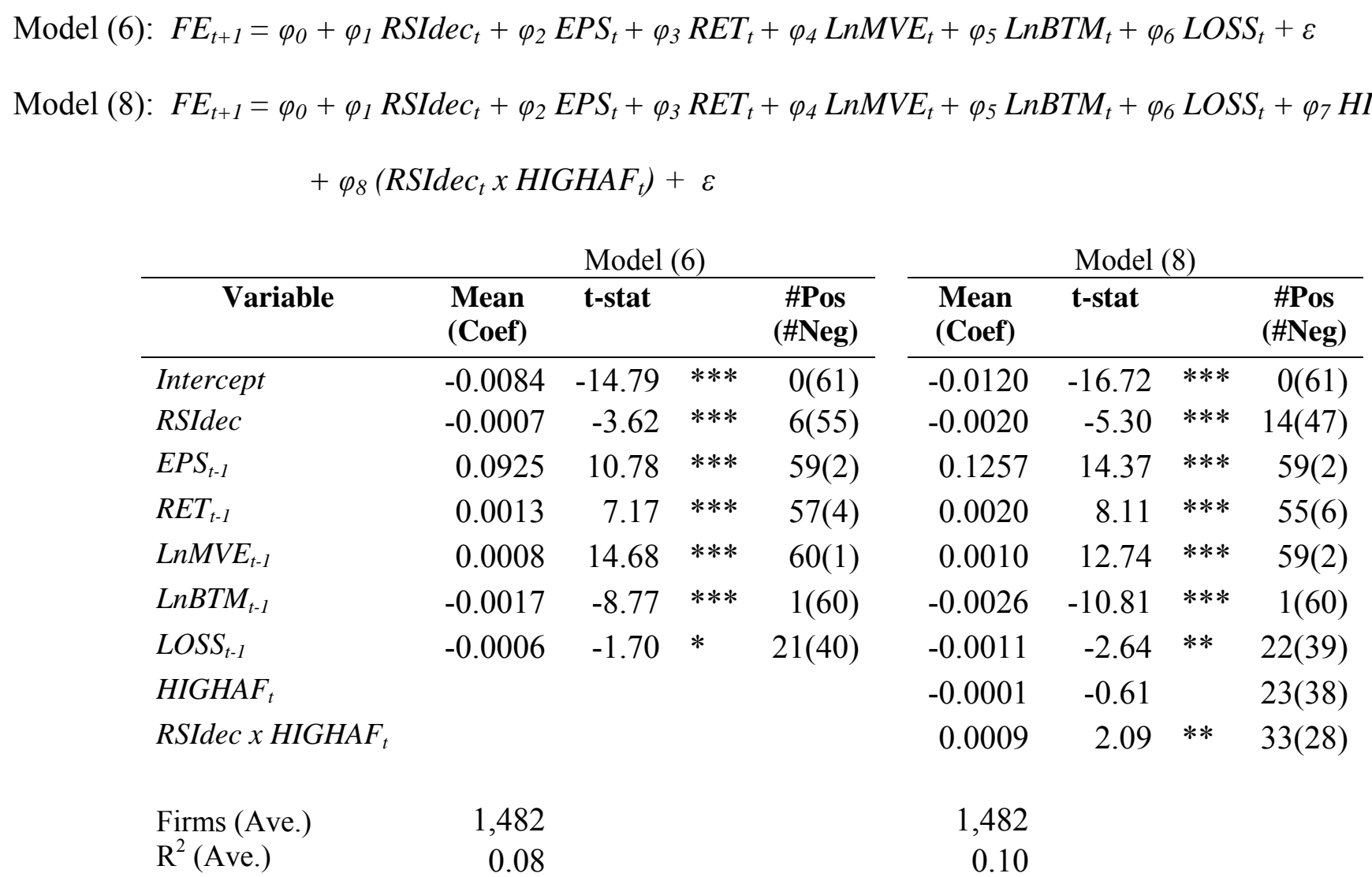

*,**,*** indicates significant at the $p<0.10,0.05,0.01$ level respectively. See Table 1 for variable definitions. The number of firms and $\mathrm{R}^{2}$ reported are the averages across the quarterly cross-sectional regressions. 
The magnitude of the coefficient suggests that on average, the quarter-two analyst forecast error is lower by $0.07 \%$ of stock price for firms with the highest RSI ratios relative to firms with the lowest RSI ratios, which is economically significant. Finally, in untabulated tests, I find that the average coefficient on RSIdec in model (6) is not significantly different from the average coefficient on RSIdec in model (5).

The results presented in Table 5 provide evidence that analyst forecasts do not fully reflect the information in RSIratio about future earnings. This suggests that analysts are inefficient with respect to earnings information contained in available short interest and implies that analysts are overly-optimistic about firms with high RSI ratios. 4.2.2. Tests of the Association between RSI Ratios and Analyst Forecast Errors for High Versus Low Analyst Following

Next, I investigate a condition under which I expect more of the information in RSIratio about future earnings to be embedded in analyst forecasts. Pownall and Simko (2005) find that abnormal returns around short-spikes are significantly more negative for firms with low analyst following than for firms with high analyst following. This implies that short-sellers play a less important role as information intermediaries when analyst following is high. I test this implication by investigating whether analyst forecasts reflect significantly more of information in RSI ratios about future earnings for firms with high versus low analyst following using the following models:

$$
\begin{aligned}
F E_{t}=\psi_{0}+ & \psi_{1} \text { RSIdec }_{t}+\psi_{2} \text { EPS }_{t-1}+\psi_{3} \text { RET }_{t-1}+\psi_{4} \text { LnMVE }_{t-1}+\psi_{5} \operatorname{LnBTM}_{t-1} \\
& +\psi_{6} \text { LOSS }_{t-1}+\psi_{7} \text { HIGHAF }_{t}+\psi_{8}\left(\text { RSIdec }_{t} x H I G H A F_{t}\right)+\varepsilon \\
& \text { and }
\end{aligned}
$$




$$
\begin{aligned}
F E_{t+1}=\varphi_{0} & +\varphi_{1} \text { RSIdec }_{t}+\varphi_{2} \text { EPS }_{t}+\varphi_{3} \text { RET }_{t}+\varphi_{4} \text { LnMVE }_{t}+\varphi_{5} \text { LnBTM }_{t} \\
& +\varphi_{6} \text { LOSS }_{t}+\varphi_{7} \text { HIGHAF }_{t}+\varphi_{8}\left(\text { RSIdec }_{t} x H I G H A F_{t}\right)+\varepsilon,
\end{aligned}
$$

where:

$H I G H A F=$ Indicator variable set equal to one if the analyst following as reported by $\mathrm{I} / \mathrm{B} / \mathrm{E} / \mathrm{S}$ is greater than the sample median of 3 analysts, and zero otherwise; ${ }^{30}$ and

All other variables and subscripts as defined previously.

In models (7) and (8), I add a control variable for the analyst following $(H I G H A F)$ and the interaction (RSIdec $x$ HIGHAF) to allow the coefficient on RSIdec to vary across levels of analyst following. I expect the coefficients on the interactions, $\psi_{8}$ and $\varphi_{8}$, to be positive, which would suggest that more of the earnings information in RSIdec is embedded into analyst forecasts when analyst following is high than when it is low.

The results for quarter-one forecast errors are presented in Table 5, Panel A. In model (7), I find that the mean coefficient on the interaction (RSIdec $x H I G H A F)$ is positive and significant $\left(\psi_{8}=0.0007 ; p\right.$-value $\left.<0.05\right)$. The coefficient is positive in 41 of the 61 quarterly regressions $\left(\chi^{2}=7.23 ; p<0.01\right)$, which allows me to reject the null hypothesis that the percentage of positive coefficients is $50 \%$. In untabulated tests, I find that the sum of the coefficients on RSIdec and (RSIdec $x H I G H A F)$ is negative and significant $\left(\psi_{1}+\psi_{8}=-0.0005 ; p\right.$-value $\left.<0.05\right)$. I find similar evidence for quarter-two forecast errors as presented in Panel B. In model (8), I find that the mean coefficient on the interaction (RSIdec $x H I G H A F)$ is positive and significant $\left(\varphi_{8}=0.0009 ; p\right.$-value $<$

\footnotetext{
${ }^{30}$ In untabulated sensitivity tests, I re-estimate models (7) and (8) using decile rankings of the analyst following. The results are qualitatively similar to those presented using the indicator variable approach.
} 
$0.05)$, but the coefficient is positive in only 33 of the 60 quarterly regressions $\left(\chi^{2}=0.41\right.$; $p$-value $>0.10)$. In untabulated tests, I also find that the sum of the coefficients on RSIdec and (RSIdec $x$ HIGHAF) is negative and significant $\left(\varphi_{1}+\varphi_{8}=-0.001 ; p\right.$-value $<$ 0.05). Together, the results suggests that analyst forecasts are more efficient with respect to short interest information when the analyst following is high than when it is low and that the information in short interest is not fully reflected in returns even for firms with high analyst following. ${ }^{31}$ Thus, these analyses extend Pownall and Simko (2005) by providing evidence that short-sellers play an especially important role as earnings-information intermediaries when analyst following is low.

\subsection{Adjusting Analyst Forecasts for Short Interest}

The results presented thus far are consistent with $H 1$. In this sub-section, I investigate a practical implication of these results for investors. Specifically, the results imply that analyst forecasts can be improved (i.e., made less biased and more accurate) by adjusting for information in short interest about future earnings. I test this implication by examining whether the historic association between RSI ratios and analyst forecast error can be used to reduce forecast error and squared-error. For the high short interest sample, I adjust analyst forecast with short interest information using

\footnotetext{
${ }^{31}$ Prior research finds that analyst following is positively associated with the information environment of the firms (O'Brien and Bhushan 1990). Thus, an alternative explanation for this result is that HIGHAF is merely acting as an indicator of the quality or level of the information environment. In untabulated tests, I examine this alternative by interacting RSIdec with the decile ranking of firm size, which is another common proxy for the firm's information environment. I find that the average coefficient on RSIdec remains negative and significant and the average coefficient on the interaction term RSIdec $x$ HIGHAF remains positive and significant. I also find that the average coefficient on the interaction of RSIdec and firm size is insignificantly different from zero. Thus, the finding that analyst forecasts are more efficient with respect to short interest information when the analyst following is high than when it is low is not related to differences in the information environment reflected in firm size.
} 
the following procedure. First, I estimate the following model separately for each fiscal quarter:

$$
F E_{t}=\omega_{0}+\omega_{1} \operatorname{RSIdec}_{t}+\varepsilon
$$

where all variables and subscripts are defined previously.

Second, I predict the analyst forecast error for the next fiscal quarter using the estimated coefficients from model (7) and the firm's next-quarter RSI decile. I then adjust the consensus earnings forecast by the predicted forecast error. For example, I estimate model (7) using data from 2000-Q1 and use the estimated $\omega_{0}$ and $\omega_{1}$ coefficients to adjust the consensus analyst forecast in 2000-Q2.

Table 6 reports the results of the adjustments to analyst forecasts using the mechanical procedure just described. I find that the unadjusted forecasts produce an average forecast error of $-0.14 \%$ of stock price and the adjusted forecasts produce an average forecast error of $-0.02 \%$ of stock price. ${ }^{32}$ The reduction in error due to the adjustment of $0.12 \%$ is statistically significant ( $t$-stat $=5.72 ; p$-value $<0.01$ ). I also find that the unadjusted mean forecasts is significantly different from zero in 50 of 60 quarters and that after the adjustment, this number is reduced by more than half to 24 of 60 quarters. ${ }^{33}$ Finally, I find that the mean squared error is significantly lower for the adjusted forecasts relative to the unadjusted forecasts $(t$-stat $=3.07 ; p$-value $<0.01)$. These results demonstrate the potential for reducing bias and increasing accuracy by adjusting analyst forecast for short interest information.

\footnotetext{
${ }^{32}$ In an untabulated tests, I find that the adjusted forecast error is not significant different than zero.

${ }^{33}$ The number of quarters drops from 61 to 60 due to my use of lagged coefficients to adjust the analyst forecasts.
} 
TABLE 6

Comparisons of Error and Squared-Error of Unadjusted Analyst Forecasts to Forecasts Adjusted with Short Interest Information.

\begin{tabular}{|c|c|c|c|c|}
\hline & $\begin{array}{c}\text { Unadjusted } \\
\text { Forecasts }\end{array}$ & $\begin{array}{l}\text { Adjusted } \\
\text { Forecasts }\end{array}$ & $\begin{array}{l}\text { Reduction } \\
\text { in Error }\end{array}$ & $\begin{array}{c}\text { t-stat } \\
\left(\chi^{2}\right)\end{array}$ \\
\hline $\begin{array}{l}\text { Mean error as a percent of } \\
\text { stock price }\end{array}$ & $-0.14 \%$ & $-0.02 \%$ & $0.12 \%$ & 5.72 \\
\hline $\begin{array}{l}\text { \# of quarters with mean } \\
\text { error significantly } \\
\text { (insignificantly) different } \\
\text { from zero }\end{array}$ & $50(10)$ & $24(36)$ & & \\
\hline $\begin{array}{l}\text { Mean squared error as a } \\
\text { percent of stock price } * \\
100\end{array}$ & 0.0191 & 0.0185 & 0.0006 & 3.07 \\
\hline $\begin{array}{l}\text { \# of quarters with lower } \\
\text { (higher) squared error }\end{array}$ & & & $45(15)$ & (15.00) \\
\hline
\end{tabular}

*,**,*** indicates significant at the $p<0.10,0.05,0.01$ level respectively. The unadjusted (raw) analyst forecasts are adjusted using the following procedure. I estimate model (7) separately for each fiscal quarter: $L F E_{t}=\omega_{0}+\omega_{1} R S I d e c+\varepsilon$. I predict the analyst forecast error for the next fiscal quarter using the estimated coefficients $\omega_{0}$ and $\omega_{1}$ and the firm's next-quarter RSI decile. I then adjust the consensus earnings forecast by the predicted forecast error.

The mean error $(E P S$ - forecasted $E P S)$ and squared error $(E P S \text { - forecasted } E P S)^{2}$ for the unadjusted and adjusted forecasts are based on the time-series of 61 quarterly measures using the High Short Interest Sample $(\mathrm{N}=50,388)$. The reduction in error is calucated as the mean quarterly difference between the unadjusted and adjusted error and squared error. 


\subsection{The Incremental Information Content of Analyst Forecast Revisions for Future}

\section{Returns beyond Short Interest}

\subsubsection{Multivariate Tests}

In this section of the dissertation, I address my second research question by investigating whether analyst earnings forecast revisions contain information that is useful for predicting future abnormal returns beyond the information available in short interest. I measure abnormal returns as the realized daily return cumulated over the period beginning the day after the last consensus earnings forecast date and ending 180 days later (approximately six-months) minus the corresponding value-weighted market return for the same period. ${ }^{34,35}$ I begin the return accumulation period the day after the last consensus forecast date so that the RSI ratio and analyst forecast revision information is available at the time the position is taken (see Figure 2). I label the resulting market-adjusted, buy-and-hold return ABRET6.

I investigate the association between analyst forecast revisions and future abnormal returns using the following model:

$$
\begin{gathered}
\text { ABRET6 }_{t}=\theta_{0}+\theta_{1} \text { FREV }_{t}+\theta_{2} \text { RET }_{t}+\theta_{3} \text { LnMVE }_{t}+\theta_{4} \text { LnBTM }_{t} \\
+\theta_{6} \text { RSIdec }_{t}+\varepsilon
\end{gathered}
$$

where:

ABRET6 $=\quad$ Market-adjusted buy-and-hold return for the six-month period beginning the day after the forecast revision date;

\footnotetext{
${ }^{34}$ If a firm delists during the return accumulation period, I compound the delisting return with the buyand-hold return and assume the liquidating proceeds are reinvested in the market portfolio (i.e., the abnormal return is zero) for the remainder of the return accumulation period.

${ }^{35}$ The results are qualitatively similar using return windows of 90- days.
} 
FFEPS $=\quad$ First consensus analyst forecast for quarterly earnings per share issued after the prior quarter's earnings announcement, scaled by the beginning of quarter stock price [COMPUSTAT data14];

FREV $=\quad$ Analyst forecast revision measured as LFEPS minus FFEPS, scaled by the beginning of quarter stock price [COMPUSTAT data14]; and

all other variables and subscripts as defined previously.

In model (10), I test whether the analyst forecast revision is positively associated with future abnormal returns $\left(\theta_{1}>0\right)$. A significantly positive coefficient on FREV is consistent with $H 2$, which posits that forecast revisions contain information that is useful for predicting returns beyond the information available in short interest. I expect a negative coefficient on RSIdec $\left(\theta_{6}<0\right)$, consistent with the finding that short interest levels are negatively associated with future abnormal returns (e.g., Asquith and Meulbroek 1996; Dechow et al. 2001; Desai et al. 2002; Asquith et al. 2005). I include momentum, size and book-to-market to control for risk factors known to predict abnormal returns (Fama and French 1992, 1995; Carhart 1997).

In Table 7, I first present the estimation results for model (10) without controlling for the information in short interest. In Panel A, the mean coefficient on FREV is positive and statistically significant $\left(\theta_{1}=0.9826 ; p\right.$-value $\left.<0.05\right)$. I find that the coefficient on FREV is positive in 46 of the 61 quarterly regressions. The percentage of positive coefficients allows rejection of the null hypothesis that the percentage is $50 \%$ $\left(\chi^{2}=15.75 ; p\right.$-value $\left.<0.01\right)$. I also find that the coefficient on each of the three risk factors is significant in the expected direction.

In Table 7, Panel B I present the estimation results for model (10) after controlling for the information in short interest. Consistent with $H 2$, the mean 
coefficient on FREV remains positive and statistically significant $\left(\theta_{1}=0.8903 ; p\right.$-value $<$ 0.05 ) and is positive in 45 of the 61 quarterly regressions. The percentage of positive coefficients allows rejection of the null hypothesis that the percentage is $50 \%\left(\chi^{2}=\right.$ 13.79; $p$-value $<0.01)$. As expected, I also find that the coefficient on RSIdec is negative and significant $\left(\theta_{6}=-0.0430 ; p\right.$-value $\left.<0.01\right)$, suggesting that short interest contains information about future abnormal returns.

\subsubsection{Portfolio Tests based on Short Interest and Analyst Forecast Revisions}

In this sub-section, I investigate a practical implication of $H 2$. The results presented in Table 7 reveal that analyst forecast revisions contain information that is useful for predicting abnormal returns beyond the information in short interest. This implies that investors could improve returns predictions using short interest by incorporating information in analyst forecast revisions about future returns. I test this implication by calculating return spreads for extreme portfolios (i.e., return for the highest portfolio minus return for the lowest portfolio) formed using short-interest alone to return spreads for portfolios formed using both short-interest and the sign of the analyst forecast revisions.

I begin by estimating abnormal returns for the six months following the formation of portfolios formed based on the magnitude of the RSI ratio. I test whether the abnormal returns to each portfolio are significantly different from zero using $t$-tests based on the time-series means and standard errors, and report the results in Table 8 . In Panel A, I observe a nearly monotonic negative association between the RSI ratio portfolios and future abnormal returns, ranging from 3.0\% ( $p$-value $<0.01)$ for firms 


\section{TABLE 7}

The Association between Analyst Forecast Revisions and Subsequent Abnormal Returns with and without Controlling for Short Interest

Model (10): ABRET6 $_{t}=\theta_{0}+\theta_{1}$ FREV $_{t}+\theta_{2}$ RET $_{t}+\theta_{3}$ LnMVE $_{t}+\theta_{4}$ LnBTM $_{t}+\theta_{6}$ RSIdec $_{t}+\varepsilon$

Panel A: Without Controlling for Short Interest

\begin{tabular}{|c|c|c|c|c|c|c|c|c|}
\hline Variable & $\begin{array}{l}\text { Mean } \\
\text { (Coef) }\end{array}$ & t-stat & & $\begin{array}{c}\text { \#Pos } \\
\text { (\#Neg) }\end{array}$ & $\begin{array}{l}\text { Mean } \\
\text { (Coef) }\end{array}$ & t-stat & & $\begin{array}{c}\text { \#Pos } \\
\text { (\#Neg) }\end{array}$ \\
\hline Intercept & 0.0657 & 2.97 & $* * *$ & $41(20)$ & 0.0643 & 2.87 & $* * *$ & $40(21)$ \\
\hline$F R E V_{t}$ & 0.9826 & 2.54 & $* *$ & $46(15)$ & 0.8903 & 2.33 & $* *$ & $45(16)$ \\
\hline$R E T_{t}$ & 0.0177 & 2.52 & $* *$ & $43(18)$ & 0.0162 & 2.28 & $* *$ & $42(19)$ \\
\hline $\operatorname{LnMVE}_{t}$ & -0.0075 & -2.28 & $* *$ & $28(33)$ & -0.0053 & -1.53 & & $28(33)$ \\
\hline $\operatorname{LnBTM}_{t}$ & 0.0147 & 1.78 & $*$ & $37(24)$ & 0.0115 & 1.44 & & $37(24)$ \\
\hline RSIdec & & & & & -0.0430 & -4.34 & $* * *$ & $18(43)$ \\
\hline Firms (Ave.) & 1,482 & & & & 1,482 & & & \\
\hline R2 (Ave.) & 0.03 & & & & 0.03 & & & \\
\hline
\end{tabular}

*,***** indicates significant at the $p<0.10,0.05,0.01$ level respectively. See Table 1 for variable definitions. The number of firms and $\mathrm{R}^{2}$ reported are the averages across the quarterly cross-sectional regressions. 


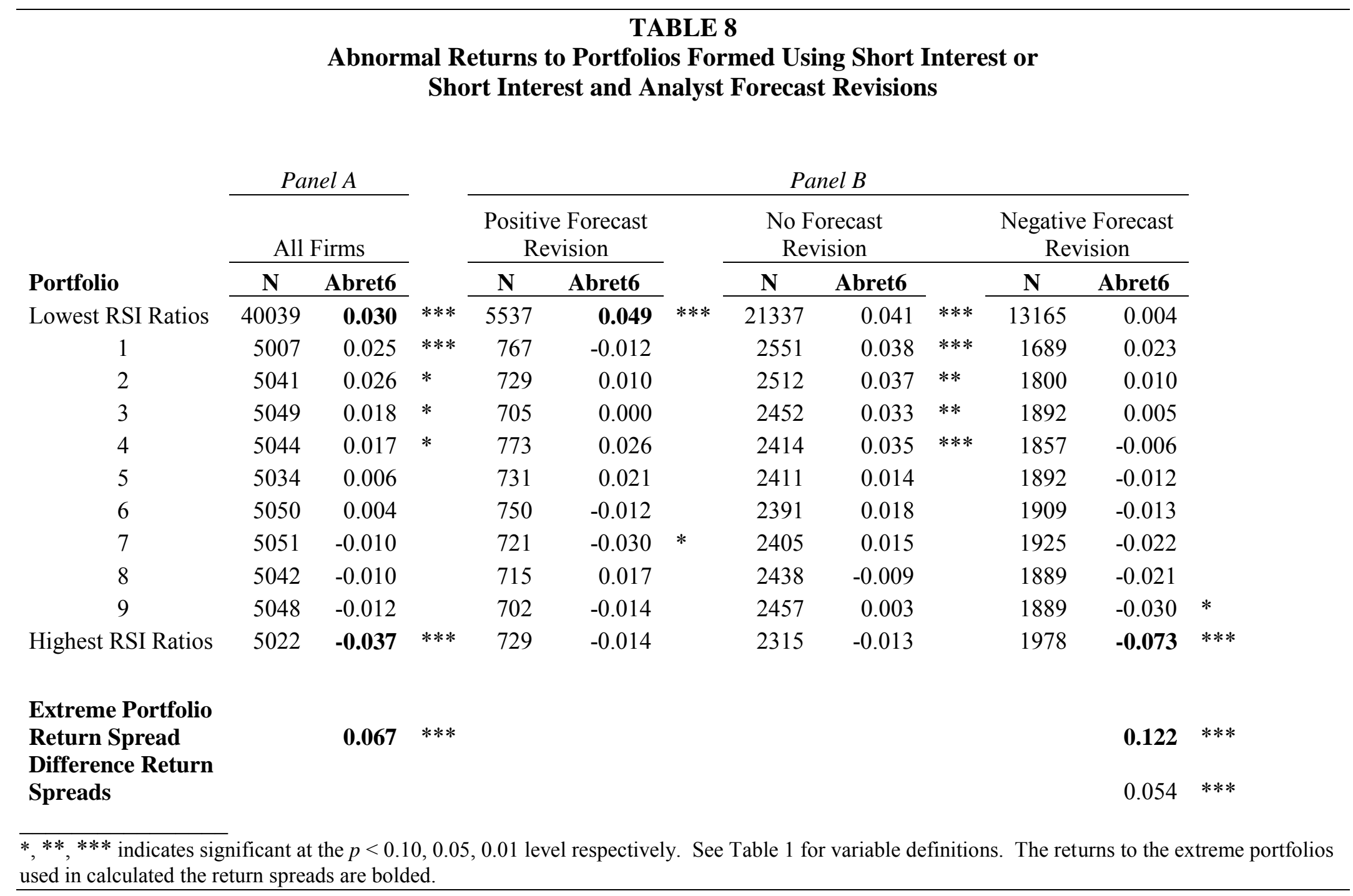




\section{FIGURE 4}

Six-Month Abnormal Returns to Portfolios Formed Using Short Interest or Short Interest and Analyst Forecast Revisions

RSI Ratio Porfolio Returns (ABRET6)

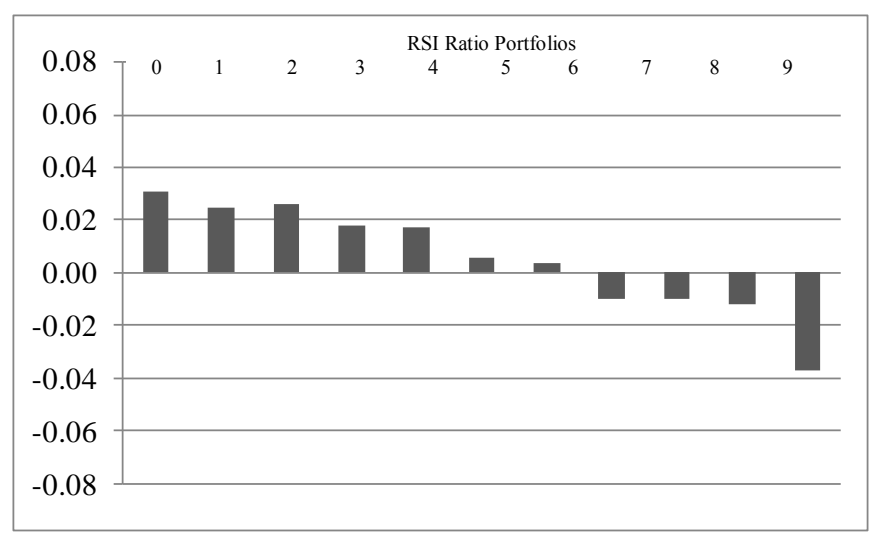

RSI Ratio/Forecast Revision Portfolio Returns (ABRET6)

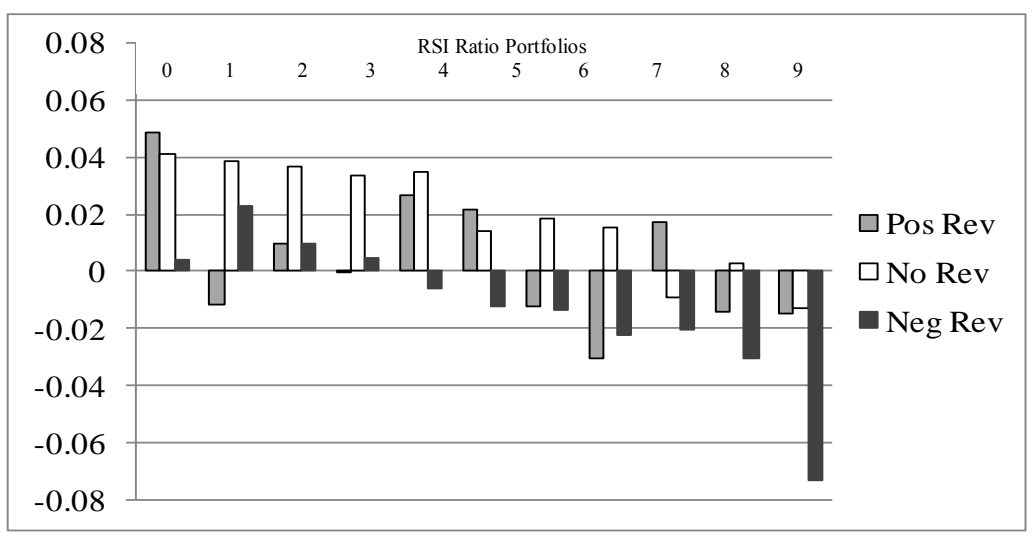

Firm-quarters with less than $0.5 \%$ of outstanding shares sold short are grouped into the RSI portfolio 0 . Firm-quarters with more than $0.5 \%$ of outstanding shares sold short are grouped into portfolios $1-10$ based on the magnitude of the RSIratio. Each RSI portfolio is partition into threepartfolios based on the sign of the consensus analyst forecast revision. Pos Rev consists of firm where LFEPS - FFEPS $>0$; No Rev consists of firms where LFEPS - FFEPS = 0; and Neg Rev consists of firms where LFEPS - FFEPS $<0$. Variable Definitions: ABRET6 is the market-adjusted buy-andhold return, measured as the realized daily return cumulated over the period beginning the day after the last consensus earnings forecast date and ending 180 days later (approximately six-months) minus the corresponding value-weighted market return for the same period. 
with the lowest RSI ratios to $-3.7 \%$ ( $p$-value $<0.01)$ for firms with the highest RSI ratios. I find that the spread in returns between the extreme portfolios is $6.7 \%$ ( $p$-value $<$ 0.01). A graph of the returns is provided in Figure 4.

Next, I incorporate information in analyst forecasts by partitioning each RSI ratio portfolio into three portfolios based on the sign of the forecast revision (i.e., positive revision, no revision, or negative revision). The six-month abnormal return to each of these portfolios is presented in Table 8, Panel B and is graphed in Figure 4. I find that the extreme portfolios based on consistent signals from short-sellers and analysts produce the largest abnormal returns. Specifically, the portfolio of stocks with the lowest RSI ratios and positive forecast revisions (good news - good news) earns an average abnormal return of $4.9 \%(p$-value $<0.01)$ over the next six months. On the opposite extreme, the portfolio of stocks with the highest RSI ratios and negative forecast revisions (bad news - bad news) earns an average abnormal return of $-7.3 \%$ ( $p$ value $<0.01)$. Thus the spread in returns between these extreme portfolios is $12.2 \%(\mathrm{p}$ value $<0.01$ ), which is significantly greater than the spread in returns using the extreme portfolios formed based on the magnitude of the RSI ratio alone of $6.7 \%$ (p-value $<$ $0.01)$.

The results presented in Table 8, Panel $\mathrm{B}$, also reveal significant differences within the extreme RSI ratio portfolios. Specifically, for the portfolios of stocks with the lowest RSI ratios, the average abnormal return for firms with positive forecast revisions of $4.9 \%$ is significantly greater than the average abnormal return for firms with negative forecast revisions of $0.4 \%$ ( $p$-value $<0.01$; untabulated). On the opposite extreme, for 
the portfolio of stocks with the highest RSI ratios, the average abnormal return for firms with negative forecast revisions of $-7.3 \%$ is significantly greater than the average abnormal return for firms with positive forecast revisions of $-1.4 \%$ ( $p$-value $<0.01$; untabulated).

In sum, the results presented in Table 8 and Figure 4 demonstrate the benefits of refining signals from short interest about future returns using information contained in analyst forecast revisions.

\subsubsection{Four-Factor Regressions}

Next, I address whether the portfolio returns estimated in Table 9, Panels A and $\mathrm{B}$, are robust to controls for omitted factors related to risk which are correlated with returns such as the market return, size, book-to-market, and momentum. I estimate the following firm-specific, model (firm subscripts omitted):

$$
R_{d}-R F_{d}=\alpha+\gamma_{1}\left(R M_{d}-R F_{d}\right)+\gamma_{2} S M B_{d}+\gamma_{3} H M L_{d}+\gamma_{4} U M D_{d}+\varepsilon,
$$

where:

$d=\quad$ Day indicator;

$R=\quad$ Raw stock return on day $d ;$

$R F=\quad$ One-month treasury bill rate divided by the number of trading days in the month;

$R M=\quad$ Value-weight return on all NYSE, AMEX, and NASDAQ stocks on day $d$;

$S M B=\quad$ Return on a portfolio of small stocks less the return on a portfolio of big stocks on day $d$;

$H M L=\quad$ Return on a portfolio of high book-to-market stocks less the return on a portfolio of low book-to-market stocks on day $d$; and 
$U M D=\quad$ Return on a portfolio of stocks that were past winners less the return on the portfolio of stocks that were past winners. ${ }^{36}$

In each fiscal quarter, I estimate model (11) separately for each firm using the daily stock returns for the 180-day period beginning the day after the last consensus analyst forecast date. This yields separate coefficient estimates for each firm-quarter. The intercept, $\alpha$, estimates the average daily abnormal return for a particular firm over the estimation period. ${ }^{37}$ A positive (negative) intercept indicates that the firm has performed better (worse) than would be expected after controlling for the market, size, book-to-market, and momentum risk factors. Each quarter, I average the firm-specific coefficient estimates across all firms within a particular portfolio. This yields a timeseries of average coefficient estimates for each portfolio. I then assess statistical significance by calculating a $t$-statistic based on the time-series means and standard errors for each portfolio.

In Table 9, I present the estimation results for model (11) using portfolios formed based on the magnitude of RSI ratios only. The results are consistent with the results presented in Table 8 . I find a monotonic negative relationship between the RSI ratio portfolios and the intercept, $\alpha$, ranges from 4.5 basis points per trading day for the firms with the lowest RSI ratios to -2.5 basis points per trading day for firms with the highest RSI ratios. The spread in returns between the extreme portfolios is 7.0 basis points and is statistically significant $(\mathrm{p}<0.01)$. Given the average number of trading days in the

\footnotetext{
${ }^{36}$ I obtained the data on the four-factors from Ken French's website: http://mba.tuck.dartmouth.edu /pages/faculty/ken.french/data_library.html.

${ }^{37}$ Since I use daily returns to estimate model (11), the results are tabulated in terms of percentage points such that an alpha of 0.045 represents 4.5 basis points per trading day.
} 
TABLE 9

Four-Factor Regression Results for Portfolios Formed Using Short Interest

Model (11): $R_{d}-R F_{d}=\alpha+\gamma_{1}\left(R M_{d}-R F_{d}\right)+\gamma_{2} S M B_{d}+\gamma_{3} H M L_{d}+\gamma_{4} U M D_{d}+\varepsilon$

\begin{tabular}{rcccccccccc}
\hline $\begin{array}{l}\text { RSI } \\
\text { Port. }\end{array}$ & $\begin{array}{c}\text { Alpha } \\
\text { Mean }\end{array}$ & & $\begin{array}{c}\text { RM-RF } \\
\text { Mean }\end{array}$ & & $\begin{array}{c}\text { SMB } \\
\text { Mean }\end{array}$ & $\begin{array}{c}\text { HML } \\
\text { Mean }\end{array}$ & \multicolumn{3}{c}{$\begin{array}{c}\text { UMD } \\
\text { Mean }\end{array}$} \\
\hline 0 & $\mathbf{0 . 0 4 5}$ & $* * *$ & 0.896 & $* * *$ & 0.755 & $* * *$ & 0.310 & $* * *$ & -0.065 & $* * *$ \\
1 & 0.027 & $* * *$ & 1.089 & $* * *$ & 0.685 & $* * *$ & 0.227 & $* * *$ & -0.065 & $* * *$ \\
2 & 0.020 & $* * *$ & 1.129 & $* * *$ & 0.679 & $* * *$ & 0.250 & $* * *$ & -0.066 & $* * *$ \\
3 & 0.023 & $* * *$ & 1.152 & $* * *$ & 0.700 & $* * *$ & 0.207 & $* * *$ & -0.074 & $* * *$ \\
4 & 0.019 & $* * *$ & 1.187 & $* * *$ & 0.704 & $* * *$ & 0.192 & $* * *$ & -0.079 & $* * *$ \\
5 & 0.016 & $* *$ & 1.226 & $* * *$ & 0.780 & $* * *$ & 0.196 & $* * *$ & -0.109 & $* * *$ \\
6 & 0.010 & $*$ & 1.222 & $* * *$ & 0.790 & $* * *$ & 0.129 & $* * *$ & -0.149 & $* * *$ \\
7 & 0.003 & & 1.245 & $* * *$ & 0.805 & $* * *$ & 0.059 & $*$ & -0.180 & $* * *$ \\
8 & 0.004 & & 1.246 & $* * *$ & 0.862 & $* * *$ & -0.045 & & -0.173 & $* * *$ \\
9 & 0.000 & & 1.311 & $* * *$ & 0.919 & $* * *$ & -0.059 & & -0.199 & $* * *$ \\
10 & $\mathbf{- 0 . 0 2 5}$ & $* * *$ & 1.337 & $* * *$ & 0.951 & $* * *$ & -0.107 & $* *$ & -0.210 & $* * *$
\end{tabular}

\title{
Extreme Portfolio Spread
}

$0.070 * * *$

\begin{abstract}
$*, * *, * * *$ indicates significant at the $p<0.10,0.05,0.01$ level respectively. I estimate model (9) separately for each firm-quarter using the daily stock returns for the 180-day period beginning the day after the last consensus analyst forecast date. This yields separate coefficient estimates for each firmquarter. I then average the quarterly firm-specific coefficient estimates across all firms within a particular portfolio. This yields a time-series of average coefficient estimates for each portfolio. I assess statistical significance by calculating a t-statistic based on the time-series means and standard errors for each portfolio. The estimates are stated in terms of daily percentage points (i.e., an alpha of 0.045 represents 4.5 basis points per trading day). The extreme portfolios used to calculate the return spread are bolded.
\end{abstract}

estimation period of 125 days across the full sample, this return spread translates into a 6-month abnormal return of approximately $9.14 \%$ (calculated as $\mathrm{e}^{0.0007 \times 125}$ ).

With respect to the coefficients (i.e., risk-factor loadings) on the control variables, I find that portfolios formed based on the magnitude of short interest are 
positively associated with market risk and negatively associated with firm size, book-tomarket, and momentum. Thus, I find that short-sellers target small growth stocks with high systematic risk and negative momentum on average, which is consistent with prior research (e.g., Dechow et al. 2001; Asquith et al. 2005).

In Table 10, I present the estimation results for model (11) using portfolios formed based on the magnitude of the RSI ratio and the sign of the consensus forecast revision. The results in Panels $\mathrm{A}, \mathrm{B}$, and $\mathrm{C}$ are for $\mathrm{RSI}$ portfolios with positive, no, and negative forecast revisions, respectively. Across all three panels, I find that the lowest RSI ratio portfolio has the highest $\alpha$ and the highest RSI ratio portfolio has the lowest $\alpha$. As reported in Panel C, the return spread between the portfolio of stocks with the lowest RSI ratio and positive forecast revisions (good news - good news) and the portfolio of stocks with the highest RSI ratio and negative forecast revisions (bad news - bad news) is 9.3 basis points per trading day (or approximately $12.3 \%$ over the next 6 months). This return spread is significantly greater than the return spread of 7 basis points (reported in Table 10) using the extreme portfolios formed based on the magnitude of RSI ratios only ( $p$-value $<0.05)$. 
TABLE 10

Four-Factor Regression Results for Portfolios Formed Using Short Interest and Analyst Forecast Revisions

Model (11): $R_{d}-R F_{d}=\alpha+\gamma_{1}\left(R M_{d}-R F_{d}\right)+\gamma_{2} S M B_{d}+\gamma_{3} H M L_{d}+\gamma_{4} U M D_{d}+\varepsilon$

Panel A: Positive Forecast Revisions

\begin{tabular}{|c|c|c|c|c|c|c|c|c|c|c|}
\hline $\begin{array}{l}\text { RSI } \\
\text { Port. }\end{array}$ & $\begin{array}{l}\text { Alpha } \\
\text { Mean } \\
\end{array}$ & & $\begin{array}{c}\text { RM-RF } \\
\text { Mean }\end{array}$ & & $\begin{array}{l}\text { SMB } \\
\text { Mean } \\
\end{array}$ & & $\begin{array}{l}\text { HML } \\
\text { Mean }\end{array}$ & & $\begin{array}{l}\text { UMD } \\
\text { Mean }\end{array}$ & \\
\hline 0 & 0.046 & $* * *$ & 0.956 & $* * *$ & 0.770 & $* * *$ & 0.335 & $* * *$ & 0.008 & \\
\hline 1 & 0.010 & & 1.134 & $* * *$ & 0.598 & $* * *$ & 0.294 & $* * *$ & -0.029 & \\
\hline 2 & 0.017 & & 1.142 & $* * *$ & 0.613 & $* * *$ & 0.333 & $* * *$ & 0.033 & \\
\hline 3 & 0.005 & & 1.174 & $* * *$ & 0.614 & $* * *$ & 0.255 & $* * *$ & 0.044 & \\
\hline 4 & 0.015 & & 1.235 & $* * *$ & 0.664 & $* * *$ & 0.307 & $* * *$ & 0.067 & $*$ \\
\hline 5 & 0.020 & & 1.239 & $* * *$ & 0.737 & $* * *$ & 0.227 & $* * *$ & -0.022 & \\
\hline 6 & 0.000 & & 1.293 & $* * *$ & 0.778 & $* * *$ & 0.135 & $* *$ & -0.013 & \\
\hline 7 & -0.009 & & 1.282 & $* * *$ & 0.852 & $* * *$ & 0.132 & $*$ & 0.053 & \\
\hline 8 & 0.010 & & 1.283 & $* * *$ & 0.843 & $* * *$ & -0.097 & & -0.074 & \\
\hline 9 & 0.001 & & 1.305 & $* * *$ & 0.845 & $* * *$ & -0.047 & & -0.048 & \\
\hline 10 & -0.015 & & 1.339 & $* * *$ & 0.932 & $* * *$ & -0.244 & $* *$ & -0.110 & \\
\hline
\end{tabular}

Panel B: No Forecast Revision

\begin{tabular}{|c|c|c|c|c|c|c|c|c|c|c|}
\hline $\begin{array}{l}\text { RSI } \\
\text { Port. }\end{array}$ & $\begin{array}{l}\text { Alpha } \\
\text { Mean }\end{array}$ & & $\begin{array}{c}\text { RM-RF } \\
\text { Mean }\end{array}$ & & $\begin{array}{l}\text { SMB } \\
\text { Mean } \\
\end{array}$ & & $\begin{array}{l}\text { HML } \\
\text { Mean } \\
\end{array}$ & & $\begin{array}{l}\text { UMD } \\
\text { Mean } \\
\end{array}$ & \\
\hline 0 & 0.054 & $* * *$ & 0.879 & $* * *$ & 0.756 & $* * *$ & 0.294 & $* * *$ & -0.041 & $* * *$ \\
\hline 1 & 0.035 & $* * *$ & 1.109 & $* * *$ & 0.713 & $* * *$ & 0.182 & $* * *$ & 0.022 & \\
\hline 2 & 0.028 & $* * *$ & 1.120 & $* * *$ & 0.698 & $* * *$ & 0.191 & $* * *$ & 0.009 & \\
\hline 3 & 0.036 & $* * *$ & 1.125 & $* * *$ & 0.686 & $* * *$ & 0.082 & $*$ & -0.019 & \\
\hline 4 & 0.034 & $* * *$ & 1.175 & $* * *$ & 0.710 & $* * *$ & 0.072 & & -0.011 & \\
\hline 5 & 0.019 & $* *$ & 1.202 & $* * *$ & 0.759 & $* * *$ & 0.135 & $* *$ & -0.020 & \\
\hline 6 & 0.016 & $* *$ & 1.199 & $* * *$ & 0.800 & $* * *$ & 0.032 & & -0.066 & $*$ \\
\hline 7 & 0.014 & & 1.240 & $* * *$ & 0.825 & $* * *$ & -0.055 & & -0.114 & $* * *$ \\
\hline 8 & 0.004 & & 1.242 & $* * *$ & 0.860 & $* * *$ & -0.127 & $*$ & -0.071 & $*$ \\
\hline 9 & 0.009 & & 1.293 & $* * *$ & 0.909 & $* * *$ & -0.197 & $* * *$ & -0.124 & $* * *$ \\
\hline 10 & -0.010 & & 1.317 & $* * *$ & 0.932 & $* * *$ & -0.171 & $* * *$ & -0.128 & $* * *$ \\
\hline
\end{tabular}


TABLE 10 (Continued)

Panel C: Negative Forecast Revision

\begin{tabular}{rcccccccccc}
\hline $\begin{array}{l}\text { RSI } \\
\text { Port. }\end{array}$ & $\begin{array}{c}\text { Alpha } \\
\text { Mean }\end{array}$ & $\begin{array}{c}\text { RM-RF } \\
\text { Mean }\end{array}$ & $\begin{array}{c}\text { SMB } \\
\text { Mean }\end{array}$ & $\begin{array}{c}\text { HML } \\
\text { Mean }\end{array}$ & \multicolumn{3}{c}{$\begin{array}{c}\text { UMD } \\
\text { Mean }\end{array}$} \\
\hline 0 & 0.028 & $* * *$ & 0.904 & $* * *$ & 0.757 & $* * *$ & 0.329 & $* * *$ & -0.134 & $* * *$ \\
1 & 0.025 & $* *$ & 1.040 & $* * *$ & 0.662 & $* * *$ & 0.234 & $* * *$ & -0.211 & $* * *$ \\
2 & 0.009 & & 1.140 & $* * *$ & 0.686 & $* * *$ & 0.292 & $* * *$ & -0.200 & $* * *$ \\
3 & 0.013 & $*$ & 1.206 & $* * *$ & 0.780 & $* * *$ & 0.344 & $* * *$ & -0.166 & $* * *$ \\
4 & 0.002 & & 1.187 & $* * *$ & 0.725 & $* * *$ & 0.281 & $* * *$ & -0.216 & $* * *$ \\
5 & 0.009 & & 1.241 & $* * *$ & 0.804 & $* * *$ & 0.271 & $* * *$ & -0.247 & $* * *$ \\
6 & 0.004 & & 1.218 & $* * *$ & 0.787 & $* * *$ & 0.248 & $* * *$ & -0.301 & $* * *$ \\
7 & 0.002 & & 1.235 & $* * *$ & 0.771 & $* * *$ & 0.137 & $* * *$ & -0.358 & $* * *$ \\
8 & 0.007 & & 1.227 & $* * *$ & 0.861 & $* * *$ & 0.058 & & -0.317 & $* * *$ \\
9 & -0.012 & & 1.318 & $* * *$ & 0.951 & $* * *$ & 0.102 & $*$ & -0.374 & $* * *$ \\
10 & $\mathbf{- 0 . 0 4 6}$ & $* * *$ & 1.358 & $* * *$ & 0.967 & $* * *$ & -0.008 & & -0.348 & $* * *$
\end{tabular}

Extreme Portfolio Spread

$0.093 * * *$

Difference in Extreme Portfolio Spread

$0.022 * *$

\begin{abstract}
*,**,*** indicates significant at the $p<0.10,0.05,0.01$ level respectively. I estimate model (9) separately for each firm-quarter using the daily stock returns for the 180-day period beginning the day after the last consensus analyst forecast date. This yields separate coefficient estimates for each firmquarter. I then average the quarterly firm-specific coefficient estimates across all firms within a particular portfolio. This yields a time-series of average coefficient estimates for each portfolio. I assess statistical significance by calculating a t-statistic based on the time-series means and standard errors for each portfolio. The estimates are stated in terms of daily percentage points (i.e., an alpha of 0.045 represents 4.5 basis points per trading day). The extreme portfolios used to calculate the return spread are bolded.
\end{abstract}




\section{CONCLUSION}

The objective of this study is to investigate whether short-sellers and financial analysts play complementary roles as information intermediaries in the capital markets by developing distinct information about future firm performance that is useful to investors. I investigate these two intermediaries because they both predict future firm performance, but they are likely to develop different types of value-relevant information, consistent with their incentives.

The first main finding is that the relative short interest ratio contains useful information for predicting earnings beyond the information in analysts' earnings forecasts. I find that the relative short interest ratio is negatively associated with subsequent analyst forecast errors, suggesting that analyst forecasts do not fully incorporate the information in the relative short interest ratio about future earnings in their forecasts. This implies that, on average, analysts are inefficient (i.e., overlyoptimistic) about firms with high short-interest levels. However, additional tests reveal that analyst inefficiency with respect to short interest is significantly reduced for firms with high analyst following relative to firms with low analyst following suggesting that short-sellers play a particularly important role as information intermediaries when analyst following is low. Finally, I demonstrate that analyst forecasts can be improved (i.e., made less biased and more accurate) by adjusting forecasts using short interest information.

The second main finding is that analyst forecast revisions contain information that is useful for predicting returns beyond the information in the relative short interest 
ratio and after controlling for returns from common risk factors (i.e., market return, size, book-to-market, and momentum). I demonstrate that returns predictions based on short interest can be refined by incorporating information in the sign of the analyst forecast revision. Specifically, I find that portfolios constructed using consistent signals from short-sellers and analysts (i.e., lowest RSI ratios and positive forecast revision or highest RSI ratios and negative forecast revision) produce significantly larger spreads in future abnormal returns (adjusted for risk factors) than portfolios constructed using signals from short-sellers alone.

From a practical perspective, this study provides two investment implications. First, the results suggest that investors who use analyst forecasts to make investment decisions (e.g., in valuation models) can benefit from adjusting the analyst forecasts using short interest information. Second, the results suggest that investors can benefit from taking long positions in stocks with low RSI ratios and positive consensus forecast revisions and that they should be particularly wary of holding long positions in stocks with high RSI ratios and negative consensus forecast revisions. These implications are important because they highlight the benefits of using multiple sources for information about future firm performance, particularly when the intermediaries providing the information are likely to use different information sets or to use similar information sets differently.

Taken together, the results suggest that short-sellers and financial analysts develop reliable, complementary information about future firm performance, and that predictions based on information from one intermediary can be improved by 
incorporating information provided by the other intermediary. This study adds to the emerging notion that short-sellers potentially play a role as information intermediaries in the capital markets and complements prior research by providing additional evidence that short-sellers possess value-relevant information. In addition, this study contributes to several streams of academic research. The results contribute to the earnings prediction literature by showing that short interest positions contain information that is useful for predicting earnings levels and changes disclosed in the next two earnings announcements. The results contribute to the analyst forecast literature by documenting that analyst forecasts do not fully reflect short interest information. Finally, the results contribute to the short interest literature by demonstrating that the signal in high levels of short interest (e.g., bad news may be imminent) can be further refined by using analyst forecast revisions.

Several unresolved issues emerge from this study. The results demonstrate that short-sellers act as if they use information to anticipate future earnings, but do not establish that they explicitly forecast earnings. It is also unclear which information sets short-sellers (e.g., financial statements) use to take their positions. Future research might focus on identifying the information sets short-sellers use to predict price declines and in assessing whether accounting information plays a significant role in forming their predictions. The results also suggest that the consensus analyst forecast is inefficient with respect to short interest information; however, the source of this inefficiency is currently unexplored. Investigating the factors associated with short interest inefficiency of individual analysts is another interesting avenue for future research. Finally, while it 
is clear that short interest information has predictive content, there is still relatively little evidence of a significant investor response to disclosures of short interest and no evidence (to my knowledge) of managers' responses to the same. I believe this to be a promising area of future research. 


\section{REFERENCES}

Abarbanell, J. 1991. Do analysts' earnings forecasts incorporate information in prior stock price changes? Journal of Accounting and Economics 14 (2): 147-165.

, and V. Bernard. 1992. Tests of analysts' overreaction/underreaction to earnings information as an explanation for anomalous stock price behavior. Journal of Finance 47 (3): 1181-1207.

, and B. Bushee. 1997. Fundamental analysis future earnings, and stock prices. Journal of Accounting Research 35 (Spring): 1-24.

Akbas, F, E. Boehmer, B. Erturk, and S. Sorescu. 2008. Why Do Short Interest Levels Predict Stock Returns? Working Paper, Texas A\&M University.

Ali, A., A. Klein, and J. Rosenfeld. 1992. Analysts' use of information about permanent and transitory earnings components in forecasting annual EPS. The Accounting Review 67 (January): 183-198.

Asquith, P., and L. Meulbroek. 1996. An empirical investigation of short interest. Working Paper, Harvard Business School.

, P. Pathak, and J. Ritter. 2005. Short interest, institutional ownership, and stock returns. Journal of Financial Economics 78 (2): 243-276.

Barth, M., and A. Hutton. 2004. Analyst earnings forecast revisions and the pricing of accruals. Review of Accounting Studies 9 (1): 59-96.

Beaver, W. 1968. The information content of annual earnings announcements. Journal of Accounting Research 6 (Spring): 67-92.

Boehme, R., B. Danielson, and S. Sorescu. 2007. Short sale constraints, differences of opinion, and overvaluation. Working Paper, Texas A\&M University.

Boehmer, E., C. Jones, and X. Zhang. 2008. Which shorts are informed? Journal of Finance 63 (April): 491-527.

, and E. Kelley. 2007. Institutional investors and the informational efficiency of prices. Working Paper, Texas A\&M University.

Bradshaw, M., S. Richardson, and R. Sloan. 2001. Do analysts and auditors use information in accruals? Journal of Accounting Research 39 (June): 45-74. 
Brent, A., D. Morse, and K. Stice. 1990. Short interest: Explanations and tests. Journal of Financial and Quantitative Analysis 25 (June): 273-289.

Brown, L., P. Griffin, R. Hagerman, and M. Zmijewski. 1987. An evaluation of alternative proxies for the market's assessment of unexpected earnings. Journal of Accounting and Economics 9 (2): 159-193.

Cao, B., D. Dhaliwal, A. Kolasinski, and A. Reed. 2007. Bears and numbers: Investigating how short sellers exploit and affect earnings-based pricing anomalies. Working Paper, Unversity of Arizona.

Carhart, M. 1997. On persistence in mutual fund performance. Journal of Finance 52 (March): 57-82.

Chan, L., N. Jegadeesh, and J. Lakonishok. 1996. Momentum strategies. Journal of Finance 51 (December): 1681-1713.

Christophe, S. , M. Ferri, and J. Angel. 2004. Short-selling prior to earnings announcements. Journal of Finance 59 (August): 1845-1875.

Collins, D., S. Kothari, and J. Rayburn. 1987. Firm size and the information content of prices with respect to earnings. Journal of Accounting and Economics 9 (2): 111138.

Danielsen, B., and S. Sorescu. 2001. Why do option introductions depress stock prices? A study of diminishing short sale constraints. Journal of Financial and Quantitative Analysis 36 (December): 451-484.

Das, S., C. Levine, and K. Sivaramakrishnan. 1998. Earnings predictability and bias in analysts' earnings forecasts. The Accounting Review 73 (April): 277-294.

Daske, H., S. Richardson, and A. Tuna. 2005. Do short sale transactions precede bad news events? Working paper, University of Mannheim and University of Pennsylvania.

Dechow, P., A. Hutton, L. Meulbroek, and R. Sloan. 2001. Short-sellers, fundamental analysis, and stock returns. Journal of Financial Economics 61 (1): 77-106.

Desai, H., S. Krishnamurthy, and K. Venkataraman. 2006. Do short sellers target firms with poor earnings quality? Evidence from earnings restatements. Review of Accounting Studies 11 (1): 71-90. 
, and 2007. On distinguishing between valuation and arbitrage motivated short selling. Working Paper, Southern Methodist University.

, K. Ramesh, S. Thiagarajan, and V. Bala. 2002. An investigation of the informational role of short interst in the Nasdaq market. The Journal of Finance 57 (October): 2263-2287.

Diamond, D., and R. Verrecchia. 1987. Constraints on short-selling and asset price adjustment to private information. Journal of Financial Economics 18 (2): 277 311.

Eames, M., and S. Glover. 2003. Earnings predictability and the direction of analysts' earnings forecast errors. The Accounting Review 78 (July): 707-724.

Easterwood, J., and S. Nutt. 1999. Inefficiency in analyst's earnings forecasts: Systematic misreaction or systematic optimism? Journal of Finance 54 (October): 1777-1797.

Efendi, J., M. Kinney, and E. Swanson. 2005. Can short sellers anticipate accounting restatements?: Working Paper, Texas A\&M University.

Fama, E., and K. French. 1992. The cross-section of expected stock returns. Journal of Finance 47 (June): 427-465.

, and 1995. Size and book-to-market factors in earnings and returns. Journal of Finance 50 (March): 131-155.

, and J. D. MacBeth. 1973. Risk, return, and equilibrium: Empirical tests. Journal of Political Economy 81 (3): 607-636.

Francis, J., and D. Philbrick. 1993. Analysts' decisions as products of a multi-task environment. Journal of Accounting Research 31 (Autumn): 216-230.

, and L. Soffer. 1997. The relative informativeness of analysts' stock recommendations and earnings forecast revisions. Journal of Accounting Research 35(Autumn): 193-211.

, M. Venkatachalam, and Y. Zhang. 2008. Do short sellers convey information about changes in fundamentals? Working Paper, Duke University.

Givoly, D., and J. Lakonishok. 1979. The information content of financial analysts' forecasts of earnings. Journal of Accounting and Economics (1): 165-185.

Gleason, C., and C. Lee. 2003. Analyst forecast revisions and market price discovery. 
The Accounting Review 78 (January): 193-225.

Griffin, P. 2003. A league of their own? Financial analysts' responses to restatements and corrective disclosures. Journal of Accounting, Auditing \& Finance 18 (4): 479-518.

. 1976. Competitive information in the stock market: An empirical study of earnings, dividends, and analysts' forecasts. Journal of Finance 31 (May): 631650 .

Hong, H., and J. Kubik. 2003. Analyzing the analysts: career concerns and biased earnings forecasts. Journal of Finance 58 (February): 313-351.

, and A. Solomon. 2000. Security analysts' career concerns and herding of earnings forecasts. RAND Journal of Economics 31 (1): 121-144.

Jones, S., and G. Larsen. 2004. The information content of short sales. Short Selling. Strategies, Risks and Rewards. Fabozzi Series. John Wiley \& Sons. Hoboken, NJ.

Kothari, S. 2001. Capital markets research in accounting. Journal of Accounting and Economics 31 (1-3):105-231.

Lim, T. 2001. Rationality and analysts' forecast bias. Journal of Finance 56 (February): 369-385.

Lys, T., and S. Sohn. 1990. The association between revisions of financial analysts' earnings forecasts and security-price changes. Journal of Accounting and Economics 13(4): 341-363.

McNichols, M., and P. O'Brien. 1997. Self-selection and analyst coverage. Journal of Accounting Research 35 (Autumn): 167-199.

Mendenhall, R. 1991. Evidence on the possible underweighting of earnings-related information. Journal of Accounting Research 29 (Spring):170-179.

Mikhail, M., B. Walther, and R. Willis. 1999. Does forecast accuracy matter to security analysts? The Accounting Review 74 (April): 185-200.

Miller, E. 1977. Risk, uncertainty, and divergence of opinion. Journal of Finance 32 (September): 1151-1168.

O’Brien, P., and R. Bhushan. 1990. Analyst following and institutional ownership. 
Journal of Accounting Research 28 (Supplement): 55-76.

Pownall, G., and P. Simko. 2005. The information intermediary role of short sellers. The Accounting Review 80 (July): 941-966.

Richardson, S., T. Hong, and P. Wysocki. 2004. The walk-down to beatable analyst forecasts: The role of equity issuance and insider trading incentives. Contemporary Accounting Research 21 (4): 885-924.

Rogers, W. 1993. Regression standard errors in clustered samples. Stata Technical Bulletin 13: 19-23.

Securities and Exchange Commission (SEC). 1999. Short Sales. SEC Concept Research No. 34-42037. File S7-24-99. Washington D.C: Government Printing Office.

Senchack, A., and L. Starks. 1993. Short-sale restrictions and market reaction to shortinterest announcements. Journal of Financial and Quantitative Analysis 28 (June): 177-194.

Shane, P., and P. Brous. 2001. Investor and (Value Line) analyst underreaction to information about future earnings: The corrective role of non-earnings-surprise information. Journal of Accounting Research 39 (September): 387-404.

Stickel, S. 1991. Common stock returns surrounding earnings forecast revisions: More puzzling evidence. The Accounting Review 66 (April): 402-416.

. 1992. Reputation and performance among security analysts. Journal of Finance 47(December): 1811-1836.

Warfield, T., and J. Wild. 1992. Accounting recognition and the relevance of earnings as an explanatory variable for returns. The Accounting Review 67 (October): 821842 . 


\section{APPENDIX A}

\section{VARIABLE DEFINTIONS}

\section{Short Interest Data:}

RSIratio Relative short interest ratio calculated as the number of shares sold short divided by the number of shares outstanding

RSIdec Decile ranking of the RSIratio. For firms with less than $0.5 \%$ of the outstanding shares sold short, RSIdec is set equal to 0 . Firms with more than $0.5 \%$ of the outstanding shares sold short are grouped into deciles based on the magnitude of the RSIratio. RSIdec is scaled to range between [0, 1$]$.

\section{COMPUSTAT Data:}

MVE

LnMVE

BTM

$\operatorname{LnBTM}$

\section{CRSP Data:}

ABRET6

RET

I/B/E/S Data:

EPS

$\triangle E P S$

LOSS
Market value of equity measured as the stock price times the number of shares outstanding (COMPUSTAT data14 x COMPUSTAT data 61).

Natural log of the market value of equity.

Book-to-market ratio measured as book equity divided by the market value of equity (COMPUSTAT data59/MVE).

Natural log of the book-to-market ratio.

Market-adjusted buy-and-hold return, measured as the realized daily return cumulated over the period beginning the day after the last consensus earnings forecast date and ending 180 days later (approximately six-months) minus the corresponding value-weighted market return for the same period. If a firm delists during the return accumulation period, I compound the delisting return with the buy-and-hold return and assume the liquidating proceeds are reinvested in the market portfolio for the remainder of the period.

The raw buy-and-hold return, measured as the realized monthly return, cumulated over the twelve-month period ending on the quarter-end date.

Actual earnings per share, scaled by the beginning of quarter stock price [COMPUSTAT data14].

Seasonal change in actual earnings per share, scaled by the beginning of quarter stock price [COMPUSTAT data14].

Indicator variable set equal to one if earnings per share as reported by $\mathrm{I} / \mathrm{B} / \mathrm{E} / \mathrm{S}$ is negative, and zero otherwise. 
LFEPS

FFEPS

$L F \triangle E P S$

FF $\triangle E P S$

$F E$

FREV

The last consensus analyst forecast for $E P S$, scaled by the beginning of quarter stock price [COMPUSTAT data14].

The first consensus analyst forecast for EPS, scaled by the beginning of quarter stock price [COMPUSTAT data14].

The last consensus analyst forecast for quarterly earnings per share issued after the prior quarter's earnings announcement, less earnings per share in the same quarter one year prior, scaled by the beginning of quarter stock price [COMPUSTAT data14]

The first consensus analyst forecast for quarterly earnings per share issued after the prior quarter's earnings announcement, less earnings per share in the same quarter one year prior, scaled by the beginning of quarter stock price [COMPUSTAT data14]

EPS minus LFEPS

LFEPS minus FFEPS 


\section{VITA}

Name: $\quad$ Michael Stephen Drake

Address: $\quad$ 460R Wehner Building

4353 TAMU

College Station, TX 77843-4353

Email Address: mdrake@mays.tamu.edu

Education: $\quad$ B.S., Accounting, Brigham Young University, 2003

M.Acc., Accounting, Brigham Young University, 2003

Ph.D., Accounting, Texas A\&M University, 2009

Experience: $\quad$ Ernst \& Young, LLP, Salt Lake City, Utah, 2003-2005

Awards: $\quad$ Deloitte Foundation Doctoral Fellowship, 2007-2009

Mays Business School Fellowship, 2005-2009

Ernst \& Young Doctoral Fellowship, 2005-2009

Texas A\&M Regents' Fellowship, 2005-2008

Certifications: Certified Public Accountant, State of Utah 